\title{
The value of magnetic resonance imaging as a biomarker for amyotrophic lateral sclerosis: a systematic review
}

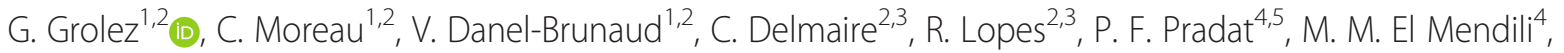
L. Defebvre ${ }^{1,2}$ and D. Devos ${ }^{1,2,6^{*}}$

\begin{abstract}
Background: Amyotrophic lateral sclerosis (ALS) is a fatal, rapidly progressive neurodegenerative disease that mainly affects the motor system. A number of potentially neuroprotective and neurorestorative disease-modifying drugs are currently in clinical development. At present, the evaluation of a drug's clinical efficacy in ALS is based on the ALS Functional Rating Scale Revised, motor tests and survival. However, these endpoints are general, variable and late-stage measures of the ALS disease process and thus require the long-term assessment of large cohorts. Hence, there is a need for more sensitive radiological biomarkers. Various sequences for magnetic resonance imaging (MRI) of the brain and spinal cord have may have value as surrogate biomarkers for use in future clinical trials. Here, we review the MRI findings in ALS, their clinical correlations, and their limitations and potential role as biomarkers.
\end{abstract}

Methods: The PubMed database was screened to identify studies using MRI in ALS. We included general MRI studies with a control group and an ALS group and longitudinal studies even if a control group was lacking.

Results: A total of 116 studies were analysed with MRI data and clinical correlations. The most disease-sensitive MRI patterns are in motor regions but the brain is more broadly affected.

Conclusion: Despite the existing MRI biomarkers, there is a need for large cohorts with long term MRI and clinical follow-up. MRI assessment could be improved by standardized MRI protocols with multicentre studies.

Keywords: Amyotrophic lateral sclerosis, Magnetic resonance imaging, Morphometry, Diffusion tensor imaging, Magnetic resonance spectroscopy, Spinal cord, Biomarkers

Abbreviations: AD, Axial diffusivity; ADC, Apparent diffusion coefficient; ALFF, Amplitude of low frequency fluctuations; ALS, Amyotrophic lateral sclerosis; ALSFRS, Amyotrophic lateral sclerosis functional rating scale; ALSFRSR, Amyotrophic lateral sclerosis functional rating scale revised; CAFS, Combined assessment of function and survival; Cho, Choline; Cr, Creatine; CSF, Cerebro spinal fluid; CST(s), Cortico-spinal tract(s); DTI, Diffusion tensor imaging; FA, Fractional anisotropy; fMRI, Functional magnetic resonance imaging; GABA, Gamma aminobutyric acid; Gln, Glutamine; Glu, Glutamate; Glx, Glutamine and glutamate; Ins, myo-inositol; MD, Mean diffusivity; MRI, Magnetic resonance imaging; MRS, Magnetic resonance spectroscopy; NAA, N-acetyl-aspartate; NiALS, Neurimaging symposium in amyotrophic lateral sclerosis; Pcr, Phosphocreatine; PD, Parkinson's disease; PLIC, Posterior limb of internal capsule; QSM, Quantitative susceptibility mapping; RD, Radial diffusivity; SWI, Susceptibility weighted imaging; VBM, Voxel-based morphometry

\footnotetext{
* Correspondence: david.devos@chru-lille.fr

'Department of Movement Disorders and Neurology, Lille University

Hospital, Faculty of Medicine, University of Lille, Lille, France

${ }^{2}$ INSERM U1171, Lille University Hospital, Faculty of Medicine, University of

Lille, Lille, France

Full list of author information is available at the end of the article
} 


\section{Background}

Amyotrophic lateral sclerosis (ALS) is a neurodegenerative disease that mainly affects the motor system. At present, the only drug to have produced an increase in patient survival in a controlled clinical trial is riluzole [1]. The condition is always fatal; the median survival time after onset is 36 [2], although there are great individual variations [3]. Although ALS is a clinically recognizable condition (in terms of the pattern of progressive upper and lower motor neuron degeneration), the clinical presentation and progression are heterogeneous [4]. Moreover, there are now strong reasons for considering a broader aetiological and pathogenic spectrum [5]. This clinical heterogeneity is observed in other neurodegenerative diseases, such as Parkinson's disease (PD). Nevertheless, it has been found that all PD patients display degeneration and iron overload of the substantia nigra, which might become a surrogate biomarker [6]. In ALS, iron overload in the motor cortex was confirmed [7] after being suspected in mouse models [8]. Ongoing drug trials in the field of neurodegenerative disease are mainly seeking to establish neuroprotection and neurorestoration. Since neuroprotection can never be unambiguously demonstrated in a given patient, the concept of disease-modifying drugs (with a slowing of the disease progression) has arisen. At present, the evaluation of a drug's clinical efficacy in ALS is based on the ALS Functional Rating Scale Revised, motor tests, survival or a combination of these measures (such as the Combined Assessment of Function and Survival (CAFS)) $[9,10]$. However, these endpoints are general, variable and late-stage measures of the ALS disease process and thus require the long-term assessment of large cohorts. These assessments are risky and expensive, which considerably limits the number of trials being conducted. A sensitive surrogate biomarker might help to (i) reduce the sample size in pilot studies, (ii) better define the sample size required in Phase III clinical trials (by comparison with clinical scales) and (iii) define endophenotypes for separate assessment in clinical trials.

Biomarkers are typically divided into "wet biomarkers" and "dry biomarkers". Wet biomarkers are biological substances that are measured in a body fluid (such as whole blood, serum, plasma, saliva or cerebrospinal fluid (CSF)). "Dry biomarkers" are based on functional scales, task performance, electrophysiology or imaging. Magnetic resonance imaging is a widely available and non-invasive technique, which makes it an appropriate candidate for biomarkers. Although early reports stated that ALS starts in the spinal cord, the initial site of neurodegeneration has not been unambiguously identified; disease may start in the spinal cord, in the motor cortex or at both sites simultaneously $[11,12]$. The development of radiological biomarkers in ALS is facilitated by the hypothesis that the pathological changes in ALS radiate out from the initial spinal and brain areas in which the most severe upper and lower motor neuron dysfunction respectively occur (from symptom onset onwards) with variability in the predominance of upper and lower motor neuron dysfunction [13]. The neurodegeneration then progresses along the motor neurons of the ventral horn of the spinal cord and into the corresponding areas of the motor cortex [13]. Despite this modelization, the pattern of onset and progression remains complex [13]. Hence, MRI of the spinal cord should be an early, sensitive marker of subtle degenerationrelated changes. However, MRI of the spinal cord is complicated by a number of technical difficulties (relative to MRI of the brain). Firstly, the magnetic field is inhomogeneous because the spinal cord is close to bone, soft tissues and air. Secondly, the spine has a small cross-sectional dimension, which thus requires high-resolution data acquisition. Thirdly, the spine is subject to motion of the CSF [14] and physiological motion due to breathing [15].

Many different MRI techniques and sequences - including voxel-based morphometry (VBM), diffusion tensor imaging (DTI), magnetic resonance spectroscopy (MRS), iron-sensitive sequences (T2*, R2* and SWI) and functional MRI (fMRI) - are available for studying ALSrelated changes in the brain or spinal cord. Hence, we reviewed the correlations between MRI findings and clinical scores in ALS, and sought to establish whether particular sequences may have value as surrogate biomarkers in this disease.

\section{Methods}

We searched the PubMed database with the following keywords: "ALS AND MRI OR amyotrophic lateral sclerosis AND magnetic resonance imaging", "ALS AND VBM OR amyotrophic lateral sclerosis AND magnetic resonance imaging ", "ALS AND MR spectroscopy OR amyotrophic lateral sclerosis AND magnetic resonance spectroscopy", "amyotrophic lateral sclerosis AND diffusion tensor imaging OR ALS AND DTI", "amyotrophic lateral sclerosis AND functional magnetic resonance imaging OR ALS AND fMRI". There was no limitation on the publication date but only publications in French or English were considered. We included (i) general MRI studies with a control group and an ALS group and (ii) longitudinal follow-up studies (even if a control group was lacking). We excluded therapeutic trials articles, reviews, studies focused only on particular subgroups of ALS patients such as cognitive impairment, genetic mutations.

\section{Results}

A total of 1336 articles were identified using database searching, 651 were recorded after duplicates removal. 
405 were excluded (not ALS, not MRI or, therapeutic clinical trials, not English or French, reviews) and 130 articles were finally excluded (studies focused only on particulars subgroups of patients, other MRI sequences or lacking of a control group). We analysed 116 articles.

\section{Brain imaging}

\section{Structural magnetic resonance imaging (Table 1)}

Three methods based on a three-dimensional, T1weighted sequence have been applied to ALS: VBM, volume analysis and the measurement of cortical thickness. As a volume-based analysis, VBM involves the automatic segmentation of grey matter and inter-subject comparison of the local grey matter density $[16,17]$. After all the data have been transformed in the same stereotaxic space, the images are partitioned and corrected for the separation between white matter, grey matter and CSF as a function of voxel intensity [17]. Measurement of cortical thickness is a surface-based technique analysis in which the white matter and pial surfaces are automatically extracted by applying image analysis packages such as Freesurfer (http://surfer.nmr.mgh.harvard.edu/).

Most of these techniques have evidenced atrophy in the precentral gyri [18-32]. However, some DTI studies used VBM to show that ALS vs. control differences in the fractional anisotropy (FA) of the precentral gyri were not due to atrophy [33, 34]. In other studies, cortical atrophy was not limited to the precentral gyri but extended to other regions of the frontal lobe [18-24, 26-28, 32, 35] - especially in apathetic patients with involvement of the cingulate cortex [27, 36]. Other regions involved include several parts of the temporal cortex [19-24, 32, 35], the hippocampus [24, 37-39], the parietal cortex (mostly in the post-central cortex [18, 21, 23, 28]) and the insula [24]. Occipital grey matter atrophy $[19,20,24,35]$ and cerebellar atrophy were less common [24]. When considering the basal ganglia, a low volume of the thalamus [22, 24, 37] and the caudate nucleus [37] have been observed. Few studies have evidenced a relative reduction in the volume of white matter (mainly in the frontal and temporal lobes) [23]. There were no marked differences in the corpus callosum [40]. Whole-brain analyses have evidenced low volumes in the neocortex, grey matter, white matter [28] and brain parenchyma [28, 32]. A longitudinal study showed (i) a volume reduction in the left subiculum, the right hippocampal area CA4 and the right dentatus gyrus and (ii) an enlargement of the ventricles in 39 of the 112 ALS patients [38].

Clinical correlations Specific MRI abnormalities have been correlated with clinical scores, the disease stage (as estimated with the original or revised ALS Functional Rating Scale (ALSFRS and ALSFRS-R, respectively), the speed of disease progression (i.e. the change in ALSFRS or ALSFRS-R score, divided by the disease duration or the time interval between two clinical assessments), the disease duration and the survival time. Lower ALSFRS or ALSFRS-R scores were associated with larger ventricles and greater volume loss in the basal ganglia [38], and volume changes in several parts of the frontal lobe (such as Brodman area 10) [18]. In another study, a higher ALSFRS-R progression rate was associated with MRI changes in the left sensorimotor area; cortical thickness was lower in patients with predominantly upper motor neuron impairment (especially in the precentral gyrus and the left paracentral lobule), whereas patients with predominantly lower motor neuron impairment showed less difference relative to controls [20]. Grey matter density was lower in the cingulate and right inferior frontal gyrus in patients with impaired emotional empathy [36]. Poor survival in ALS is correlated with volume loss in the basal ganglia and limbic structures [38]. The initial side of limb weakness in ALS patients was not correlated with contralateral brain cortical loss of volume [27]. Although atrophy was predominant in the left sensorimotor cortex [27, 28], it was not related to the side of onset [27]. A subgroup analysis (by side of onset) found more widespread atrophy in the contralateral brain cortex than in the group of ALS patients as a whole [28]. Precentral cortical thickness was lower in patients with upper motor neuron clinical features than in those with lower motor neuron clinical features and in the ALS group as a whole [29].

In a study with a post mortem T1 sequence and histological assessment, an abnormally small difference in intensity between cortical grey matter and subcortical white matter was observed not only in the motor cortex (including the precentral gyrus, supplemental motor area and premotor cortex) but also in somatosensory areas and the primary visual cortex. These signal abnormalities were linked to neuron loss and an elevated number of astrocytes [41].

\section{Diffusion tensor imaging (Table 2)}

DTI (also known as magnetic resonance tractography) is based on the random diffusion (Brownian motion) of molecules. In a spherical volume, the diffusion of water has no main direction and its diffusion in the three directions $(\lambda 1, \lambda 2$ and $\lambda 3)$ is equally likely. However, this is no longer the case in an ellipsoid or cylindrical volume and the diffusion is anisotropic. $\lambda 1$ is the volume's main axis (axial diffusivity, $\mathrm{AD}$ ) and $\lambda 2$ and $\lambda 3$ are the minor axes (radial diffusivity, RD). By analysing the diffusion of water in three directions, four parameters can be defined: $F A, R D, A D$ and mean diffusivity (MD, which is the average of diffusion in the $\lambda 1, \lambda 2$ and $\lambda 3$ axis, also referred to as the apparent diffusion coefficient (ADC)). The first three parameters describe the spatial variation 
Table 1 The main results of volumetric studies

\begin{tabular}{|c|c|c|}
\hline Publication & $\begin{array}{l}\text { Numbers of } \\
\text { patients/controls }\end{array}$ & Main results \\
\hline $\begin{array}{l}\text { Abdulla et al., } \\
{[39,80]}\end{array}$ & $58 / 29$ & Low volume in the right hippocampus \\
\hline $\begin{array}{l}\text { Agosta et al., } \\
{[21]}\end{array}$ & $25 / 18$ & $\begin{array}{l}\text { GM volume reduction in right precentral, left } \\
\text { inferior frontal cortex and temporal superior cortex. }\end{array}$ \\
\hline $\begin{array}{l}\text { Agosta et al., } \\
{[35]}\end{array}$ & $44 / 26$ & $\begin{array}{l}\text { Reduction in cortical thickness in the precentral, } \\
\text { frontal, limbic, parietal, temporal and occipital lobes. }\end{array}$ \\
\hline $\begin{array}{l}\text { Bede et al., } \\
{[37]}\end{array}$ & $39 / 44$ & $\begin{array}{l}\text { GM volume reduction in the thalamus, caudate } \\
\text { nucleus, hippocampus, left putamen. }\end{array}$ \\
\hline $\begin{array}{l}\text { Canu et al., } \\
{[23]}\end{array}$ & $23 / 24$ & $\begin{array}{l}\text { GM volume reduction in the precentral, right } \\
\text { opercular and angular cortex, WM volume reduction } \\
\text { in the frontal lobe (especially the subcortical } \\
\text { motor areas) and the temporal lobe. }\end{array}$ \\
\hline $\begin{array}{l}\text { Cerami et al., } \\
{[36]}\end{array}$ & $14 / 20$ & $\begin{array}{l}\text { Low GM density in the anterior cingulate and } \\
\text { right inferior frontal gyri. }\end{array}$ \\
\hline $\begin{array}{l}\text { Chang et al., } \\
\text { [22] }\end{array}$ & $\begin{array}{l}20(10 \text { ALS and } \\
10 \text { ALS-FTD)/22 }\end{array}$ & $\begin{array}{l}\text { GM volume reduction in the precentral, frontal and } \\
\text { temporal cortex and left posterior thalamus. }\end{array}$ \\
\hline $\begin{array}{l}\text { Chapman et al., } \\
\text { [40] }\end{array}$ & $25 / 22$ & $\begin{array}{l}\text { No intergroup difference in the corpus } \\
\text { callosum area }\end{array}$ \\
\hline $\begin{array}{l}\text { Devine et al., } \\
\text { [27] }\end{array}$ & $30 / 17$ & $\begin{array}{l}\text { GM volume reduction in the left precentral cortex, } \\
\text { left frontal gyrus, medial frontal gyri and anterior } \\
\text { cingulate gyri. }\end{array}$ \\
\hline
\end{tabular}

Ellis et al., [26] 16 (8 bulbar onset GM volume reduction in the superior, middle and

Grosskreutz et al., $17 / 17$

[18]

Kassubek et al., $\quad 22 / 22$ [32]

Meadcroft et al., $\quad 8 / 6$

2014

Mezzapesa et al., $\quad 16 / 9$

[19]

Mezzapesa et al., 29/20

[20]

Sach et al., [33] 15/12

Sage et al., [34] 28/26

Schuster et al., $\quad 93$ (60 ALS, 17 with [25]

[24]

Verstraete et al., $\quad 12 / 12$

[30] and $8 \mathrm{limb}$ onset)/8 medial frontal cortex. WM volume reduction in the right frontal cortex.

Main clinical correlations

Verbal memory test performance is correlated with the left hippocampal volume.

Negative with ALSFRS-R and DD.

DPR is correlated with the mean cortical thickeness of left sensorimotor cortex.

Not available.

Not available.

Not available.

Not available.

Not available.

Increased GM volume reduction in the dominant (left) motor cortex irrespective to the side of limb onset. Asymmetric GM reduction of the left somatosensory cortex and the temporal gyri in in right limb onset ALS

Compared to limb onset ALS, bulbar onset ALS showed GM volume reduction in the brainstem, the cerebellum and in the fusiform gyri (BA 34) and WM volume reduction along the left corticospinal tract.

ALSFRS-R correlated positively with GM volume reduction in the right medial frontal gyrus (BA 10).

Negative with ALSFRS-R and DD.

Not available.

Not available.

Different patterns of volume reduction in ALS group, high UMN burden, spinal onset and faster progression compared to controls.

Not available.

Not available.

No difference -study not designed to voxel-based morphometry. with lower motor neuron involvement, with focal LMN)/67 cortex.

Different patterns of volume reduction in ALS subgroups: bulbar and spinal UMN signs, only spinal UMN signs, classical ALS, UMN ALS-variants, LMN ALS-variants or sites of onset compared to controls. GM reduction is most important in the left precentral cortex in bulbar onset vs. limb onset. No correlations of MRI with DPR, DD and ALSFRS-R.

Not available.

GM volume reduction in the precentral, frontal and temporal cortex (especially the hippocampus), the parietal and occipital cortex, the thalamus and the cerebellum. No difference in WM.

GM reduction in the right and left precentral cortex. Not available. 
Table 1 The main results of volumetric studies (Continued)

\begin{tabular}{|c|c|c|c|}
\hline $\begin{array}{l}\text { Walhout et al., } \\
\text { [29] }\end{array}$ & $\begin{array}{l}153(112 \mathrm{ALS}, 19 \\
\text { UMN, } 19 \text { LMN)/60 }\end{array}$ & $\begin{array}{l}\text { GM reduction in the right and (predominantly) left } \\
\text { precentral cortex and the right paracentral cortex. }\end{array}$ & $\begin{array}{l}\text { Bulbar and arms ALSFRS-R subscores are correlated } \\
\text { with cortical thickness of corresponding precentral } \\
\text { cortex areas of the motor homunculus. DPR is } \\
\text { correlated with the thickness of the right inferior } \\
\text { temporal cortex, the postcentral cortex and the } \\
\text { right paracentral cortex. }\end{array}$ \\
\hline $\begin{array}{l}\text { Westenberg } \\
\text { et al., } 2014\end{array}$ & $112 / 60$ & $\begin{array}{l}\text { GM volume reduction in the hippocampus and } \\
\text { left subiculum. }\end{array}$ & $\begin{array}{l}\text { Larger ventricles are correlated to a lower ALSFRS-R } \\
\text { score. Smaller basal ganglia, smaller limbic structures } \\
\text { and larger ventricles are associated with shorter } \\
\text { survival. }\end{array}$ \\
\hline Zhang et al., [28] & $43 / 43$ & $\begin{array}{l}\text { GM reduction in the left precentral cortex, left } \\
\text { supplemental area and left postcentral gyrus. } \\
\text { Reduction in neocortex volume, GM and WM } \\
\text { volume and brain parenchymal fraction. }\end{array}$ & $\begin{array}{l}\text { GM volume reduction is most important in the motor } \\
\text { cortex of the contralateral hemisphere of the limb of } \\
\text { onset. ALSFRS is positively correlated with GM density } \\
\text { in the left postcentral cortex and DPR is negatively } \\
\text { correlated with GM density in the right precentral cortex }\end{array}$ \\
\hline $\begin{array}{l}\text { Zhu et al., } \\
{[31,87]}\end{array}$ & $22 / 22$ & GM reduction in the right and left precentral cortex. & $\begin{array}{l}\text { Negative with DD, DPR and all other clinical } \\
\text { parameters. }\end{array}$ \\
\hline
\end{tabular}

GM grey matter, WM white matter, BA Brodman area, $D D$ disease duration, DPR Disease progression rate, UMN upper motor neuron

of water movement and are related to the orientation of the studied structures. In contrast, MD corresponds to the mean displacement of the water molecules within the volume. The main application of DTI is the analysis of the anatomical bundles that compose the white matter of the brain and the spinal cord [42-44]. Whereas DTI corresponds to the analysis of the above-mentioned parameters in a defined volume, tractography corresponds to the analysis of a complete white matter tract.

Fractional anisotropy in ALS Low FA along entire corticospinal tracts (CSTs) is the most common observation in patients with ALS [34, 45-58]. However, some studies have only reported low FA in one or several parts of a CST: the subcortical white matter of the precentral gyrus $[23,24,30,33,59-65]$, the corona radiata $[24,60-62$, 66-68], the posterior limb of the internal capsule (PLIC) $[24,33,60,62,63]$, the cerebral peduncles $[21,59,61]$ and the pons [61]. Lastly, only one study failed to observe a difference in FA along a CST in ALS patients by region of interest approach whereas tract based spatial statistics (TBSS) showed decreased FA in corona radiate and corpus callosum [68].

Low FA has also been observed in other regions: the frontal lobe (excluding the CST) [21, 24, 33, 34, 45, 52, 56, $57,61,64]$, the cingulum [60], the corpus callosum [21, $33,45,50,52,58,61,67-69]$, the parietal lobe [24, 34, 45], the temporal lobe [21], parahippocampal areas [61], the hippocampus [34], the insula [34, 52], the cerebellum [61] and the thalamus $[24,33,53]$. In a whole-brain comparison, many other small areas of ALS-modified white matter tracts were observed [70].

A tractography study revealed that the CST volumes of ALS patients are lower than in controls [71]. A DTI study using a tract of interest-based fibre tracking found that the radiological results mirrored the neuropathological staging system [72], suggesting that the disease process extended in the following sequence: the corticospinal tract (stage 1), the corticorubral and corticopontine tracts (stage 2), the corticostriatal tract (stage 3 ) and the proximal portion of the perforant pathway (stage 4) [73]. The researchers suggested that this MRI-based staging system could be used as a surrogate marker of disease progression in clinical studies of ALS.

Diffusivity in ALS The most common observation in patients with ALS is a relative increase in MD, reflecting changes in white matter tracts. The MD was elevated along entire CSTs $[51,53,69]$ and in parts of CSTs, including subcortical white matter in the precentral gyrus $[23,34,58,60,61]$, the corona radiata $[34,60]$, the PLIC $[23,34,60,74]$, the cerebral peduncles and the pons [34]. Diffusivity was also elevated in several parts of the frontal lobe $[23,24,52,58,60,61]$, the temporal lobe [23, 24, 52, 61], the hippocampal region [24, 34, 52], the parahippocampal region [60], the parietal lobe $[23,58,61]$, the insula $[23,24,52]$, the cingulum [53, $60]$, the occipital lobe [23], the cerebellum [23, 60] (especially in C9ORF72-positive patients) [75], the corpus callosum [23, 52, 60, 69] and the thalamus [53]. Conversely, two studies did not detect any differences in diffusivity in ALS patients vs. controls [21, 63].

Radial and axial diffusivity in ALS Several studies have found elevated RD and AD values in the right CST, the right cingulum and the left anterior thalamic radiations (on the basis of changes in FA or MD) [53]. In the PLIC, $\mathrm{AD}$ is low [63] and RD is elevated [67] - especially in patients presenting with T2 hyperintensities in CSTs [63]. $\mathrm{RD}$ is elevated in white matter connected to the primary motor cortex, the premotor cortex [56] and the corpus 
Table 2 The main results of DTI studies

\begin{tabular}{|c|c|c|c|c|c|}
\hline Publication & $\begin{array}{l}\text { Numbers of } \\
\text { patients/controls }\end{array}$ & Fractional anisotropy & $\begin{array}{l}\text { Mean diffusivity or apparent } \\
\text { diffusion coefficient }\end{array}$ & Radial and axial diffusivity & Main clinical correlations \\
\hline Abe et al., [64] & $7 / 11$ & $\begin{array}{l}\text { Low in parts of the right frontal } \\
\text { lobe and in the left subcortical } \\
\text { precentral area }\end{array}$ & & & Not available \\
\hline Agosta et al., [21] & $25 / 18$ & $\begin{array}{l}\text { Low in parts of CSTs, the CC, } \\
\text { parts of the frontal lobe and } \\
\text { parts of the temporal lobe }\end{array}$ & No difference & & Negative \\
\hline Bede et al., [75] & $27 / 42$ & $\begin{array}{l}\text { Low along CSTs, the CC, } \\
\text { cerebellum, brainstem, occipital } \\
\text { lobe and opercular and insular } \\
\text { regions }\end{array}$ & & $\begin{array}{l}\text { RD was low in the } \\
\text { cerebellum, brainstem, } \\
\text { occipital lobe and opercular } \\
\text { and insular regions }\end{array}$ & Not available \\
\hline Canu et al., [23] & $23 / 14$ & $\begin{array}{l}\text { Low in subcortical parts of CSTs } \\
\text { and other parts of the frontal } \\
\text { lobe }\end{array}$ & $\begin{array}{l}\text { Elevated in parts of the CSTs, left } \\
\text { postcentral gyrus, left insula, parts of the } \\
\text { left temporal lobe, right angular cortex, } \\
\text { parts of the frontal lobe, CC, parts of the } \\
\text { occipital lobe and parts of the cerebellum }\end{array}$ & & $\begin{array}{l}\text { Correlation between } \mathrm{MD} \text { in bilateral } \\
\text { orbitofrontal region and } \mathrm{DD}\end{array}$ \\
\hline Chapman et al., [67] & $21 / 21$ & $\begin{array}{l}\text { Low in the CC, corona radiata } \\
\text { and PLIC }\end{array}$ & & $\begin{array}{l}\mathrm{RD} \text { was low in the CC, } \\
\text { corona radiate and PLIC. AD } \\
\text { was elevated in the left } \\
\text { corona radiata and the } \\
\text { internal and external } \\
\text { capsules }\end{array}$ & $\begin{array}{l}\text { Correlation between FA in parts of } C C \text { and } \\
\text { ALSFRS-R and negative correlation with DD, } \\
\text { correlation between RD in parts of } C C \text { and } \\
\text { DD }\end{array}$ \\
\hline Ciccarelli et al., [45] & $26 / 41$ & $\begin{array}{l}\text { Low along CSTs, the CC, anterior } \\
\text { limb of the internal capsule, } \\
\text { external capsule, parts of frontal } \\
\text { lobe WM and postcentral gyri }\end{array}$ & & & $\begin{array}{l}\text { Correlation between DPR and FA in left } \\
\text { cerebral peduncle, right PLIC, right corona } \\
\text { radiate right WM adjascent to the } \\
\text { precentral gyrus and CC }\end{array}$ \\
\hline Ding et al., [74] & $10 / 10$ & & Elevated in the PLIC & & Not available \\
\hline Ellis et al., [51] & $22 / 20$ & Low along CSTs & Elevated along CSTs & & $\begin{array}{l}\text { Correlation between mean diffusivity in CST } \\
\text { and DD and between FA along CSTs and } \\
\text { ALS severity scale and spasticity scales. }\end{array}$ \\
\hline Filippini et al., [56] & $24 / 24$ & Low along CSTs and in the CC & & $\begin{array}{l}\text { Elevated RD in WM linked } \\
\text { to the primary motor and } \\
\text { premotor cortex and the CC }\end{array}$ & $\begin{array}{l}\text { Inverse correlation between FA and UMN } \\
\text { score along CSTs, correlation between FA } \\
\text { and ALSFRS-R and DD along CSTs }\end{array}$ \\
\hline Foerster et al., [55] & $29 / 30$ & Low along CSTs & & & $\begin{array}{l}\text { Correlation between FA and ALSFRS-R } \\
\text { along CSTs }\end{array}$ \\
\hline Iwata et al., [49] & $31 / 31$ & Low along CSTs & & & Negative \\
\hline Iwata et al., [50] & $18 / 19$ & $\begin{array}{l}\text { Low along CSTs and in the } \\
\text { motor part of the CC }\end{array}$ & Elevated along CSTs & & $\begin{array}{l}\text { Correlation between DD and FA along } \\
\text { CSTs. Inverse correlation between FA in } \\
\text { CSTs and global and localized UMN } \\
\text { impairment score and between FA along } \\
\text { CST and UMN rapidity index. }\end{array}$ \\
\hline Kassubek et al., [12, 73] & $111 / 74$ & Low along CSTs & & & Not available \\
\hline
\end{tabular}


Table 2 The main results of DTI studies (Continued)

\begin{tabular}{|c|c|c|c|c|c|}
\hline Keil et al., [61] & $24 / 24$ & $\begin{array}{l}\text { Low in parts of CSTs, } \\
\text { supplementary motor area, CC, } \\
\text { parts of the frontal lobe and the } \\
\text { parahippocampal area }\end{array}$ & $\begin{array}{l}\text { Elevated in motor areas, parts of CSTs, parts } \\
\text { of the frontal and temporal lobe, and the } \\
\text { postcentral gyrus }\end{array}$ & & $\begin{array}{l}\text { Correlation between FA along CSTs and } \\
\text { ALSFRS-R. Correlation between executives } \\
\text { functions (sfs } 36 \text { score) and FA in cerebel- } \\
\text { lum. At } 6 \text { months, negative correlation be- } \\
\text { tween FA along CSTs and DD correlation } \\
\text { between FA along CSTs and frontal WM } \\
\text { and ALSFRS-R. Correlation between FA in } \\
\text { CST at brainstem level and executives func- } \\
\text { tions, negative correlation between ADC in } \\
\text { the cerebellum and parahippocampal gyri } \\
\text { and executives functions (sfs36) }\end{array}$ \\
\hline Keller et al., [68] & $33 / 30$ & $\begin{array}{l}\text { Low in the corona radiata and } \\
\text { CC }\end{array}$ & & & Negative \\
\hline Liu et al., 2014 & 19/13 & Low along CSTs & & & $\begin{array}{l}\text { Correlation between FA along left CST and } \\
\text { ALSFRS-R }\end{array}$ \\
\hline Menke et al., [77] & $\begin{array}{l}21 / 0 \text { (follow-up } \\
\text { study) }\end{array}$ & $\begin{array}{l}\text { Progressive reduction in the } \\
\text { PLIC }\end{array}$ & & & Correlation between FA at baseline and DPR \\
\hline Metwalli et al., [69] & $12 / 19$ & Low along CSTs, the CC & Elevated along CSTs, the CC & $\begin{array}{l}\mathrm{AD} \text { and } \mathrm{RD} \text { were elevated } \\
\text { along CSTs, RD was } \\
\text { elevated in the CC, parts of } \\
\text { frontal and parietal lobe }\end{array}$ & Negative \\
\hline Muller et al., 2011 & $19 / 19$ & $\begin{array}{l}\text { Low in parts of CSTs, the } \\
\text { parahippocampal area, insula } \\
\text { and brainstem }\end{array}$ & & & $\begin{array}{l}\text { Correlation between FA in parts of CSTs } \\
\text { and ALSFRS-R }\end{array}$ \\
\hline Nickerson et al., [46] & $\begin{array}{l}\text { 2/0 (follow-up } \\
\text { study) }\end{array}$ & $\begin{array}{l}\text { A linear reduction along CSTs } \\
\text { during one year follow-up }\end{array}$ & & & Not available \\
\hline Poujois et al., [65] & $19 / 21$ & $\begin{array}{l}\text { Low in CSTs from the left } \\
\text { corona radiate to the precentral } \\
\text { gyrus and in both cerebral } \\
\text { peduncles }\end{array}$ & & & $\begin{array}{l}\text { Muscular strength is lower on the right side } \\
\text { corresponding to the lower FA in the left } \\
\text { CST }\end{array}$ \\
\hline Prell et al., [60] & $17 / 17$ & $\begin{array}{l}\text { Low in parts of CSTs and the } \\
\text { cingulate gyrus }\end{array}$ & $\begin{array}{l}\text { Elevated parts of CSTs, parts of frontal lobe, } \\
\text { cingulate gyrus, parahippocampal region, } \\
\text { CC, cerebellum. }\end{array}$ & & $\begin{array}{l}\text { Correlation between FA in internal capsule } \\
\text { and contralateral strength of the lower limb. } \\
\text { Different patterns in FA and ADC of bulbar } \\
\text { and limb onset compared to controls. }\end{array}$ \\
\hline Prudlo et al., [70] & $22 / 21$ & $\begin{array}{l}\text { Low throughout the CSTs, the } \\
\text { anterior limb of the internal } \\
\text { capsule, thalamic radiations, the } \\
\text { CC, association fibres and the } \\
\text { middle cerebellar peduncle }\end{array}$ & & & $\begin{array}{l}\text { Correlation between FA in many voxels of a } \\
\text { whole DTI brain analyses with ALSFRS-R }\end{array}$ \\
\hline Pyra et al., [59] & $14 / 14$ & Low in left precentral gyrus & & & $\begin{array}{l}\text { Correlation between spasticity and ADC in } \\
\text { contralateral precentral gyrus }\end{array}$ \\
\hline Rajagopalan et al.. [63] & $47 / 10$ & $\begin{array}{l}\text { Low in the left subcortical motor } \\
\text { area and right PLIC }\end{array}$ & & $\begin{array}{l}\text { AD was low in the PLIC. RD } \\
\text { was elevated in the PLIC of } \\
\text { patients with } T 2 \\
\text { hyperintensities in the CSTs }\end{array}$ & Not available \\
\hline
\end{tabular}


Table 2 The main results of DTI studies (Continued)

\begin{tabular}{|c|c|c|c|c|c|}
\hline Rosskopf et al., [57] & $100 / 93$ & Low along CSTs & & & $\begin{array}{l}\text { Correlation between FA along CSTs and } \\
\text { ALSFRS-R }\end{array}$ \\
\hline Sach et al., [33] & $15 / 12$ & $\begin{array}{l}\text { Low in parts of CSTs, premotor } \\
\text { areas, CC and right thalamus }\end{array}$ & & & $\begin{array}{l}\text { Low FA in patients without UMN signs in } \\
\text { parts of CST, CC and right thalamus. No } \\
\text { correlation available with clinical score }\end{array}$ \\
\hline Sage et al., [34] & $28 / 26$ & $\begin{array}{l}\text { Low along CSTs and the right } \\
\text { postcentral gyrus }\end{array}$ & Elevated in parts of CSTs & & $\begin{array}{l}\text { Correlation between FA and ALSFRS in } \\
\text { several parts of CSTs and in prefrontal lobe }\end{array}$ \\
\hline Sage et al., [52] & $28 / 26$ & $\begin{array}{l}\text { Low in parts of CSTs, parts of } \\
\text { the frontal lobe, insula, } \\
\text { hippocampus, cerebral } \\
\text { peduncles and CC }\end{array}$ & $\begin{array}{l}\text { Elevated along CSTs, hippocampus, insula, } \\
\text { parts of the temporal and frontal lobe and CC }\end{array}$ & & $\begin{array}{l}\text { Correlation between FA along CSTs, in } \\
\text { prefrontal area and ALSFRS. Negative } \\
\text { correlation between MD along CST, } \\
\text { hippocampus, cerebellum, parietal and } \\
\text { temporal lobe and ALSFRS. }\end{array}$ \\
\hline Sarica et al., [53] & $14 / 14$ & $\begin{array}{l}\text { Low in right CSTs and left } \\
\text { anterior thalamic radiations }\end{array}$ & $\begin{array}{l}\text { Elevated in right CSTs, cingulum and left } \\
\text { anterior thalamic radiations }\end{array}$ & $\begin{array}{l}\mathrm{RD} \text { elevated in right CSTs } \\
\text { and left anterior thalamic } \\
\text { radiations. } \mathrm{AD} \text { elevated in } \\
\text { the right cingulum }\end{array}$ & Negative $(p \leq 0.05)$ \\
\hline Schirimrigt et al., 2007 & $10 / 20$ & $\begin{array}{l}\text { Low along CSTs (nb: study with } \\
\text { a technical objective) }\end{array}$ & & & Correlation between FA along CSTs and DD \\
\hline Stagg et al., [47] & $13 / 14$ & Low along CSTs & Elevated along CSTs & & Negative \\
\hline Tang et al., [58] & $69 / 23$ & $\begin{array}{l}\text { Low along CSTs, in frontal WM } \\
\text { and the genu of the CC }\end{array}$ & $\begin{array}{l}\text { Elevated in the centrum semi-ovale and } \\
\text { frontal and parietal WM }\end{array}$ & & Not available \\
\hline Thivard et al., [24] & $15 / 25$ & $\begin{array}{l}\text { Low along CSTs, premotor } \\
\text { cortex, right thalamus, insula, } \\
\text { parts of parietal lobe }\end{array}$ & $\begin{array}{l}\text { Elevated in the motor cortex, premotor } \\
\text { cortex, insula, hippocampus, and right } \\
\text { superior temporal gyrus }\end{array}$ & & $\begin{array}{l}\text { Correlation between FA along CST, insula, } \\
\text { premotor cortex, cingulum, precuneus, CC } \\
\text { and ALSFRS-R, negative correlation be- } \\
\text { tween FA in CC and centrum semiovale } \\
\text { and DD }\end{array}$ \\
\hline Verstraete et al., [30] & $12 / 12$ & $\begin{array}{l}\text { Low in the rostral part of CSTs } \\
\text { and the CC }\end{array}$ & & & Not available \\
\hline Wang et al., [71] & $16 / 17$ & Low CST volume in DTI & & & Negative \\
\hline Yin et al., [48] & $8 / 12$ & Low along CSTs & & & Not available \\
\hline Zhang et al., [62] & $17 / 19$ & Low in parts of CSTS & Elevated in parts of the CSTs & & $\begin{array}{l}\text { Correlation between FA in right superior } \\
\text { CST and ALSFRS-R and motor subscore of } \\
\text { ALSFRS-R }\end{array}$ \\
\hline
\end{tabular}


callosum [56, 67, 69]. Lastly, RD and AD are elevated in the cerebellum of C9ORF72-positive patients [75].

Longitudinal studies In longitudinal analyses, low FA is observed in the right superior CST [62], precentral subcortical regions, mesencephalic CSTs and parts of cerebellum [61]. FA was found to fall in a progressive, linear manner along the CSTs [34, 46, 76], and the diffusivity of the external and internal capsule was elevated [61]. $\mathrm{AD}$ is elevated in CSTs [77]. However, a recent longitudinal study found that white matter defects (as assessed by DTI) progressed much slowly that in the grey matter defects - notably in the basal ganglia [78].

Clinical correlations Many studies have found that disease progression (as defined by the change over time in the ALSFRS or ALSFRS-R score) is correlated with the changes in FA in CSTs $[24,34,45,61,62,77,79]$. Furthermore, the disease duration is correlated with FA in entire CSTs or parts of CSTs [24, 50, 54, 56, 61, 77]. Conversely, the disease duration was negatively correlated with FA in the cerebellum [61], the subcortical white matter of insula, the ventrolateral premotor cortex, the cingulum, the precuneus and the splenium of the corpus callosum [24]. Lower-limb muscle strength was correlated with the contralateral FA in CSTs [60]. Diffusivity values in CSTs and in the parietal lobe, temporal lobe and cerebellum were also correlated with disease progression [52, 79]. Diffusivity in CSTs was correlated with disease duration [79], and contralateral diffusivity in CSTs was correlated with spasticity [59].

Whereas both limb-onset patients and bulbar-onset patients differed from controls in terms of FA along CSTs, the two patient groups had similar values [60]. The CSTs were more impaired in bulbar-onset patients than in limb-onset patients when considering FA, MD and $\mathrm{RD}$ but not $\mathrm{AD}$ [80]. Tractography revealed a large number of differences between controls and patients defined as definite/probable according to the El Escorial criteria, whereas there were fewer differences between controls and a possible/suspected group [79].

Neurophysiological correlations FA in CSTs was related to the central conduction time in a transcranial magnetic stimulation study [33, 49] (Iwata et al., [49]; Sach et al., [33]).

Diagnostic accuracy An individual patient data metaanalysis of CST studies concluded that DTI lacks sufficient diagnostic discrimination [81]. The pooled sensitivity and specificity were only 0.68 and 0.73 , respectively. Researchers have also suggested that a multimodal approach (combining DTI with methods such as MRS) may be more promising [55].

\section{Magnetic resonance spectroscopy (Table 3)}

MRS is a non-invasive means of assessing brain metabolism, based on the chemical properties of molecular structures. Results are expressed as peaks. The main brain metabolites monitored with MRS include Nacetyl-aspartate (NAA), choline (Cho, a cell membrane marker), creatine $(\mathrm{Cr})$ and phosphocreatine (Pcr). The $\mathrm{Cr}+\mathrm{Pcr}$ peak is a marker of energy metabolism; the level of $\mathrm{Cr}$ is assumed to be stable and is used to calculate the metabolite ratio. At a field strength of $1.5 \mathrm{~T}$, the peaks for glutamine (Gln), glutamate (Glu, an excitatory neurotransmitter) and gamma aminobutyric acid (GABA, an inhibitory neurotransmitter) overlap to form a complex referred to as "Glx"; higher field strengths are required for more accurate quantification of this metabolites. The simple sugar myo-inositol (Ins) is absent from neurons but present in glial cells. Hence, elevated brain levels of Ins are associated with glial proliferation, whereas low levels are associated with glial destruction [82-84].

The main results for the CST concern the ratio between the NAA peak on one hand and the Cho and $\mathrm{Cr}+\mathrm{Pcr}$ peaks on the other. In ALS patients, low levels of NAA have been observed in the precentral corticosubcortical region [85-91], in the PLIC [85] and in entire CSTs [55, 59, 86, 92]. Glu and Glu + Gln were found to be elevated in the precentral corticosubcortical region and in the PLIC [85], whereas Cho was found to be elevated in the precentral region [88, 93, 94] and along the CSTs $[47,59,92]$. Levels of the inhibitory neurotransmitter GABA were low in the precentral cortex $[55,95]$, and levels of Ins were low in the precentral corticosubcortical region [89].

Whereas the above-mentioned studies used defined voxels for MRS acquisition, whole-brain spectroscopy has revealed low NAA/Cho or NAA/Cr ratios in many other regions [93].

Follow-up studies have shown a decrease in the NAA peak in the precentral cortex (with no differences for other metabolites) [96], a decrease in the NAA/Cho peak and an increase in the Cho/Cr peak [91].

Clinical correlations Patients with definite or probable ALS (according to the El Escorial criteria) had low levels of NAA and high levels of Ins and Cho in the precentral cortex. In patients with possible or suspected ALS, only Cho and (on the left side) Ins were elevated. In another study of suspected ALS patients, only right-side Ins and right-side Cho were elevated [79]. Low NAA and high Cho and Ins levels are associated with clinical disease severity [94]. Lower NAA levels in the precentral gyrus, disease duration and disease progression were intercorrelated [59], and a low NAA/Cho ratio was associated with poor survival [88]. 
Table 3 main results of magnetic resonance spectroscopy studies

\begin{tabular}{|c|c|c|c|}
\hline Publication & $\begin{array}{l}\text { Numbers of } \\
\text { patients/controls }\end{array}$ & Main results & Main clinical correlations \\
\hline Bowen et al., [94] & $18 / 12$ & $\begin{array}{l}\text { Cho and ins were elevated in the MC. NAA and } \mathrm{Cr} \\
\text { were correlated in left MC }\end{array}$ & $\begin{array}{l}\text { Correlation between ins in MC and UMN disability, } \\
\text { negative correlation between Naa in MC and UMN } \\
\text { disability, higher Cho in sever UMN disability group }\end{array}$ \\
\hline Cervo et al., [90] & $84 / 28$ & $\mathrm{NAA} /(\mathrm{Cho}+\mathrm{Cr})$ was low in the MC & Negative \\
\hline Foerster et al., [95] & $10 / 9$ & $\begin{array}{l}\text { Low gamma aminobutyric acid in the MC but not in } \\
\text { WM }\end{array}$ & Negative \\
\hline Foerster et al., [55] & $29 / 30$ & $\begin{array}{l}\text { NAA and gamma aminobutyric acid were low and } \\
\text { ins was elevated in the left MC }\end{array}$ & $\begin{array}{l}\text { Negative correlation between gamma aminobutyric } \\
\text { acid in MC and DD, correlation between Naa peak in } \\
\text { MC and ALSFRS-R }\end{array}$ \\
\hline Govind et al., [92] & $38 / 70$ & $\begin{array}{l}\text { NAA was low and Cho was elevated in most parts of } \\
\text { CST, and Cho/NAA was elevated in all parts of the } \\
\text { CSTs }\end{array}$ & $\begin{array}{l}\text { Negative correlation between Cho/Naa in the left } \\
\text { entire CST and forced vital capacity, negative } \\
\text { correlation between Cho/Naa in the left CST and } \\
\text { right and left finger tap rate, negative correlation } \\
\text { between Cho/Naa in left MC and semiovale centrum } \\
\text { and right finger tape or forced vital capacity }\end{array}$ \\
\hline Han et al., [85] & $15 / 15$ & $\begin{array}{l}\text { NAA/Cr peak was low in the MC and PLIC, Glu/Cr } \\
\text { and Glu }+ \text { GIn/Cr peaks were low in the MC and } \\
\text { PLIC }\end{array}$ & $\begin{array}{l}\text { Negative correlation between Glu + Gln/Cr with } \\
\text { Norris score }\end{array}$ \\
\hline Kalra et al., $[88,89]$ & $63 / 18$ & $\begin{array}{l}\mathrm{NAA} / \mathrm{Cho} \text { and NAA/Cr was low in the MC, and Cho/ } \\
\text { Cr was elevated in the MC }\end{array}$ & $\begin{array}{l}\text { Relation between decreased } \mathrm{Naa} / \mathrm{Cho} \text { in the } \mathrm{MC} \text { and } \\
\text { reduced survival. }\end{array}$ \\
\hline Kalra et al., $[88,89]$ & $17 / 15$ & $\begin{array}{l}\mathrm{NAA} / \mathrm{Ins}, \mathrm{NAA} / \mathrm{Cr} \text { and NAA/Cho were low in the MC, } \\
\text { and Ins/Cr was elevated in the MC }\end{array}$ & Negative $(p \leq 0.05)$ \\
\hline Liu et al., [87] & 19/13 & $\mathrm{NAA} / \mathrm{Cr}$ was low in the MC & Negative \\
\hline Lombardo et al., [79] & $32 / 19$ & $\begin{array}{l}\mathrm{NAA} / \mathrm{Cr} \text { was low and ins/Cr and } \mathrm{Cho} / \mathrm{Cr} \text { were } \\
\text { elevated in the MC. }\end{array}$ & $\begin{array}{l}\text { Abnormalities were correlated with the El Escorial } \\
\text { score }\end{array}$ \\
\hline Pohl et al., [91] & $70 / 48$ & 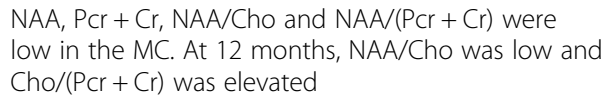 & Not available \\
\hline Pyra et al., [59] & $14 / 14$ & $\begin{array}{l}\text { NAA/Cho and NAA/Cr were low in the MC and } \\
\text { corona radiata, and Cho/Cr was elevated in the MC }\end{array}$ & $\begin{array}{l}\text { Correlation between Naa/Cho peak in } \mathrm{MC} \text { and DD, } \\
\text { negative correlation between Naa/Cho in } \mathrm{MC} \text { and } \\
\text { corona radiata and DPR }\end{array}$ \\
\hline Rooney et al., [86] & $10 / 9$ & $\begin{array}{l}\mathrm{NAA} /(\mathrm{Cho}+\mathrm{Cr}) \text { was low in the } \mathrm{MC} \text { and } \mathrm{CST} \text { but not } \\
\text { in other regions }\end{array}$ & $\begin{array}{l}\text { Correlation between } \mathrm{Naa} /(\mathrm{Cho}+\mathrm{Cr}) \text { in the } \mathrm{MC} \text { and } \\
\text { maximum finger tape rate }\end{array}$ \\
\hline Stagg et al., [47] & $13 / 14$ & NAA was low along the CSTs & $\begin{array}{l}\text { Correlation between Naa peak along CSTs and } \\
\text { ALSFRS-R }\end{array}$ \\
\hline Unrath et al., [96] & $8 / 0$ & $\begin{array}{l}\text { Progressive decrease over time in the NAA peak } \\
\text { throughout the MC }\end{array}$ & $\begin{array}{l}\text { Progressive decrease of } \mathrm{Naa} /(\mathrm{Cr}+\mathrm{Cho}) \text { in the less } \\
\text { affected hemisphere. Correlation between Naa and } \\
\text { the more or less affected side (ALSFRS subscore). } \\
\text { Correlation between Naa/(Cr }+\mathrm{Cho}) \text { and the less } \\
\text { affected side (ALSFRS subscore) }\end{array}$ \\
\hline Verma et al., [93] & $21 / 10$ & $\begin{array}{l}\text { NAA/Cho was low in the right lingual gyrus, parts of } \\
\text { the occipital lobe, left supramarginal gyrus and left } \\
\text { caudate. NAA/Cr was low in the right MC, left frontal } \\
\text { inferior operculum, right cuneus, parts of the } \\
\text { occipital lobe, left caudate and left Heschl gyrus }\end{array}$ & Not available \\
\hline
\end{tabular}

MC motor cortex, CST corticospinal tract, PLIC posterior limb of the internal capsule, WM white matter, NAA N-acetylaspartate, Cho choline, Gln glutamine, Glu glutamate, $\mathrm{PCr}$ phosphocreatine, $\mathrm{Cr}$ creatine or creatine + $\mathrm{Pcr}$ (the distinction is not relevant for interpretation), $D D$ disease duration, DPR disease progression rate

Diagnostic accuracy In a recent study, the combination of MRS and DTI yielded a sensitivity of 0.93 and a specificity of 0.85 , whereas the DTI data alone gave values of 0.86 and 0.70 , respectively [55]. A criterion combining the MRS data, hypointensity in the precentral gyri and hyperintensity in the CSTs yielded a sensitivity of 0.78 and a specificity of 0.82 ; when each of the three parameters was considered alone, the sensitivity and specificity values did not exceed 0.71 and 0.75 , respectively [90].

\section{Iron imaging}

Iron overload appears to be involved in the physiopathology of ALS [8, 97]. However, very few studies have analysed the iron content in the brain of ALS patients. A 
variety of techniques are available, including relaxometry (T2, T2* or R2*) and the susceptibility-weighted imaging $[98,99]$ (SWI, which is probably more sensitive than relaxometry [100]). Multi-echo $\mathrm{T}^{*}$ and $\mathrm{R} 2$ * sequences are sensitive to magnetic field inhomogeneities. The value of $\mathrm{R} 2 *$ is measured by voxel-by-voxel modelling of the exponential decrease in signal [101, 102]. In postmortem studies, R2* values have been found to be correlated with the iron content [103].

\section{Susceptibility-weighted imaging and quantitative susceptibility mapping (QSM)}

SWI is derived from T2* sequences and can be described as a flow-compensated, high-spatial-resolution T2* weighted sequence. The main advantage over conventional T2* sequence is better contrast [101]. QSM is based on the analysis of phase information. The main sources of phase shifts in biological tissues are the iron, calcium, lipid and myelin contents [104]. The value of QSM in ALS was confirmed in a post-mortem study, in which the iron content of grey matter was assessed more accurately than that of white matter [105].

The initial studies in the field noted a shorter T2 time in the motor cortex of most ALS patients (vs. controls) [106], although this was not confirmed a few years later [107]. Later studies found a correlation being $\mathrm{T} 2 *$ shortening and iron deposition in the microglia of the motor cortex (according to a post-mortem examination) [7, 106, 108]. Iron overload in the motor cortex was also described in SWI studies [109] and qualitative studies [100]; in the later study, there were no differences between ALS patients and controls in terms of $\mathrm{T} 2$ or $\mathrm{T} 2 \%$. A few quantitative studies have looked at white matter or deep grey matter [109, 110]. There was a trend towards iron accumulation in CST white matter in a relaxometry study [110]. Iron overload was also present in the red nucleus, substantia nigra, globus pallidus, putamen [109] and caudate nucleus [110]. The use of SWI sequences revealed widespread iron overload and myelin defects in the white matter of all brain lobes and corpus callosum [111]. A retrospective study of iron deposition in motor cortex found that quantitative susceptibility mapping was more accurate than T2*, T2 or FLAIR sequences [112].

A follow-up study has highlighted the progression of a $\mathrm{T} 2$ hypointense area in the motor cortex after 6 months, which was strongly and negative correlated with the ALSFRS score [108]. Lastly, changes in SWI sequences in the corpus callosum are correlated with the ALSFRSR score [111].

\section{Imaging of the spinal cord}

The few studies to have analysed the spinal cord revealed atrophy in the cervical and upper thoracic regions [113-115]. A DTI study reported low FA, elevated RD and a high magnetization transfer ratio in lateral segments of the cervical spinal cord [114]. Atrophy of the cervical and upper thoracic spinal cord progressed over time, whereas the DTI changes were relatively stable [115]. This observation agrees with the results of a longitudinal brain MRI study showing that grey matter defects (but not white matter defects) progressed over time [78]. Sensory pathways were also involved, with a decreased FA and an elevated MD and elevated RD in the posterior part of the cervical spinal cord [115, 116]. MRS of the cervical spinal cord revealed low $\mathrm{NAA} / \mathrm{Cr}+\mathrm{Pcr}$ and NAA/Ins peaks and an elevated Ins/Cr peak [117].

Clinical correlations Cervical and upper thoracic spinal cord atrophy was correlated with upper arm muscle strength, as measured by manual testing [114]. FA in the cervical spinal cord was correlated with the ALSFRS score. The rate of atrophy in a follow-up study was correlated with the rates of changes of an arm ALSFRS-R score and an arm strength score (in a manual test) [115]. The NAA/Cr + Pcr and NAA/Ins peaks were positively correlated with the ALSFRS-R score and forced vital capacity but negatively correlated with disease progression [117].

\section{Functional MRI}

Brain fMRI is a recent technique based on blood flow and blood-oxygen-level dependent (BOLD) contrast, which in turn are based on the neurovascular consequences of neuronal activation [118]. The paramagnetic properties of deoxyhaemoglobin lead to signal reduction in gradient echo sequences [101]. Brain fMRI sequences are acquired in the resting state or during performance of a motor, auditory, cognitive, or visual task [119-121]. The resting state sequences are quite similar to $\mathrm{T} 2 \%$ sequences [101].

In the resting state, functional connectivity is based on fluctuations of the BOLD signal. In general, seven "default" networks can be identified: default mode, executive control, visual salience, sensorimotor, dorsal attention and auditory networks [118, 122]. Functional connectivity between specific brain regions and/or networks and the rest of the brain can then be analysed [118]. Resting-state analysis can also provide information about local activation (by analysing the amplitude of low-frequency fluctuations (ALFF), for example).

The resting state Resting-state studies have evidenced the widespread reorganization of functional connectivity in ALS patients. This reorganization can be observed as either elevated functional connectivity or low functional connectivity. Functional connectivity was found to be low in several parts of the frontal lobe (the right orbitofrontal cortex, the left inferior frontal cortex [123] and 
especially the motor cortex [124]) but was elevated in the parietal lobe (the left precuneus and the right angular gyrus [123]) and the left frontoparietal network [123]. This agrees with the elevated sensorimotor connectivity of the left sensorimotor cortex with several regions of the right hemisphere (mainly the cingulate cortex, parahippocampal gyrus and cerebellum crus II) [125]. When compared with alterations of the CSTs (according to FA measurements), there were also changes in right sensorimotor connectivity; the connectivity was elevated if the CST was normal in a DTI analysis but was low if the CST was abnormal [125]. A network-by-network analysis revealed low activity in the default mode network [126] and elevated activity in the sensorimotor network (both of which include parts of the frontal lobe [126, 127], although not the same ones). Thalamic connectivity is also elevated [127].

Resting-state activity (as measured by the ALFF) was elevated in the frontal lobe (the left anterior cingulate, right superior frontal cortex [31] left medial frontal gyrus and right inferior frontal gyrus [128]), the temporal lobe (the right parahippocampal cortex and the left inferior temporal cortex) and the occipital lobe (the middle occipital cortex) [31] but low in the right fusiform gyrus, the visual cortex and right postcentral gyrus [128].

The resting-state connectivity in the frontal cortex is correlated with disease progression and duration [128]. The connectivity between the left sensorimotor cortex and the right parahippocampal gyri and fourth cerebellar lobule is correlated with the ALSFRS-R [125]. Connectivity of the dorsal part of the precentral gyri was correlated with hand strength [124]. Activity in the right parahippocampal gyri was correlated with disease progression, whereas activity in the left anterior cingulate and left temporal gyrus was correlated with cognitive parameters [31].

Activation in fMRI In motor tasks, activation of the motor cortex was elevated [129-131] and spread widely across the supplementary motor area, the premotor cortex [132] and the parietal somatosensory cortex [129, 132]. Inhibition was low [130]. Activation of the ipsilateral sensorimotor cortex was possibly linked to a compensatory mechanism in ALS [133]. A visual task was associated with poor activation of the secondary visual cortex and strong activation of associative areas, whereas an auditory task produced delayed activation in the secondary auditory cortex, and somatosensory stimulation produced prolonged activation of the right inferior frontal gyrus and right posterior insular cortex [134]. In a modified "go"/ "no-go" task, activation of the primary motor cortex, other motor areas, the frontal lobe, the insula and the cerebellum was found to decrease over a three-month period
[135]. Using another type of stimulus, activation of the hippocampus also fell after 3 months [135]. In a theoryof-mind task designed to evaluation the mirror neuron system, ALS patients displayed abnormally strong activation of the right anterior cortical areas [136]. A link between the severity of motor weakness and the pattern of activation has never been observed, although the ALSFRS-R score was correlated with the signal change in the sensorimotor cortex in one study [129]. When considering the clinical phenotype, only a bulbar-onset subgroup showed low activation of the motor cortex during tongue movements [131]. Shifts in cerebellar or hippocampal activation were correlated with the ALSFRS-R score.

\section{Discussion}

When considering the data as a whole, the most diseasesensitive MRI patterns are located in motor regions (and especially along the CST from the cortex to the spinal cord). However, ALS also affects the brain more broadly; other parts of the frontal lobe, the temporal lobe, the hippocampus, the parietal lobe, the cingulum and the insula are commonly involved, whereas the occipital lobe is less frequently involved. For most MRI parameters, patient vs. control differences are mostly apparent in the left (dominant) hemisphere. The various MRI patterns appear to reflect disease severity, progression and duration. With fMRI, abnormally high levels of activation in the motor cortex are probably related to the diseaserelated loss of inhibition. Excessive activation appears to be associated with compensation for the loss of function caused by neuron loss.

\section{Limitations of neuroimaging as a biomarker for ALS}

The low average number of participants represents the main limitation: very few published studies have featured more than 30 subjects per group (i.e. ALS and control groups). Together with the differences in the proportions of the various patient phenotypes, this explains the high variability of the results - particularly outside the motor cortex and the CSTs [137].

Only a small proportion of morphometric studies included a whole-brain analysis. The proportion is higher for DTI studies and low (only one study) for MRS. The selection of regions of interest may over-emphasize changes in the CSTs and the motor system and underemphasize changes outside these areas.

Very few studies had a longitudinal design, which is nevertheless required for the full interpretation of abnormalities. The main difficulty in setting up longitudinal studies relates to the rapid disease progression and the appearance of respiratory failure, which prevents patients from lying in the MRI for any length of time. In studies longer than 6 months, the drop-out rate is usually over $50 \%$. 
fMRI studies have highlighted both elevated activity and low activity in several parts of the brain. The main physiopathological explanations relate to a physiological compensation response or elevated activity due to the loss of inhibitory mechanisms [127].

Spinal cord imaging is a rarely applied imaging modality in ALS, despite the pivotal involvement of the anterior horn of the spinal cord in ALS [137]. Spinal cord imaging appears to be most commonly used in studies of multiple sclerosis, since all studies in this disease context found differences (relative to controls) in the cervical spinal cord. To the best of our knowledge, no studies of the whole spinal cord have been published perhaps as a result of technical obstacles.

\section{The biomarker concept}

Currently, the diagnosis of ALS is based on the revised El Escorial criteria (also known as the Airlie House criteria), which were established in 1998 and published in 2000 [138]. Although diagnosis during the course of the disease has become relatively easy, the onset of ALS can be masked by clinical overlap with many other diseases [139]. The ideal biomarker is not only sensitive and specific (for various disease phenotypes) early in the disease process but must also easy to access [140]. In ALS, the typical time interval of 12 months between the initial symptoms and disease diagnosis makes this challenge tougher still [140-142]. The best way of determining early biomarkers for ALS may be to monitor cohorts of presymptomatic patients identified by genetic studies [143]. Although wet biomarkers based on blood or CSF analysis are relatively accessible, there are many candidates and study-to-study reproducibility appears to be quite low $[5,140]$.

\section{Perspectives}

There is currently a need for a robust clinical-radiological description of ALS using MRI as a function of the disease progression, the various endophenotypes and left/right asymmetry (in terms of upper and lower motor neuron impairment, bulbar involvement, and the cognitive profile ranging from frontotemporal dementia, apathy and dysexecutive syndrome to mild attention disorders).

Despite the few number of studies, spinal cord could be a promising region of interest, although this approach is currently limited by technical post-processing difficulties and a sizeable number of large scale and longitudinal studies involving the spinal cord is needed to build stronger MRI biomarkers of the spinal cord. It may be of value to combine several techniques (e.g. atrophy mapping and measurements of the iron content in the grey matter). The results of MRI of the spinal cord are well correlated with the clinical impairment and might be a good surrogate marker.
A comprehensive analysis of MRI parameters in very large cohorts of ALS patients might reveal a radiological surrogate marker for use in clinical trials. Several points should be considered for large scale studies: in 2010, the first Neuroimaging Symposium in ALS (NiALS) had the aim of establishing consensus about the various applications of MRI to the study of ALS and the possibility of multicentre collaboration. Consensus criteria for the main MRI sequences (VBM, DTI, fMRI and spectroscopy) and the main clinical dataset were established [144]. The aim of this consensus was to lead large multicentre and longitudinal studies in imaging research or therapeutic trials [144]. <In our days, studies might better assess the most recent discovers in ALS such as genetic parameters (especially C9ORF72 expansion), the knowledge in cognitive and behavioural impairments even if the patients do not fulfil criteria for frontotemporal dementia [145]. There is still a need for longitudinal studies especially in presymptomatic and early phase of the disease [145]. Following this multicentre aim, a very recent study showed in 253 patients and 189 controls from eight international ALS specialised centre more widespread white matter tract change pooling the analyses than in single-centre analysis and reached estimation of neuropathological changes [146].

\section{Conclusion}

The MRI biomarkers appear to be well correlated with disease severity, duration and progression and are more sensitive in the brain and spinal cord motor regions. The built of MRI biomarkers is limited by the clinical various phenotypes but also by the lack of large and longitudinal studies. To date large cohorts with multicentre studies using a standardized MRI protocol are needed.

\section{Acknowledgments \\ The authors thank Dr. David Fraser (Biotech Communication, Damery, France) for editing the article. \\ Funding \\ Not applicable.}

\section{Availability of data and materials}

Data and the findings are fully available without restriction upon request to the authors.

\section{Authors' contribution}

GG, CM, VDB, CD, LD and DD: conception of the study. GG and DD: writing the first draft and the final draft. CM, VDB, CD, RL, PFP, MMEM and LD: review and critical coment. All authors have read and approved the final version of the manuscript.

\section{Competing interests}

The authors declare that they have no competing interests about this manuscript.

\section{Consent for publication}

Not applicable as this manuscript is a systematic review and not a clinical trial.

Ethics approval and consent to participate

Not applicable as this manuscript is a systematic review and not a clinical trial. 


\section{Author details}

'Department of Movement Disorders and Neurology, Lille University Hospital, Faculty of Medicine, University of Lille, Lille, France. ${ }^{2}$ INSERM U1171, Lille University Hospital, Faculty of Medicine, University of Lille, Lille, France. ${ }^{3}$ Department of Neuroradiology, Lille University Hospital, Faculty of Medicine, University of Lille, Lille, France. ${ }^{4}$ Laboratoire d'Imagerie Biomédicale, Sorbonne Universités, UPMC Univ Paris 06, CNRS, INSERM, Paris, France. ${ }^{5}$ Département des Maladies du Système Nerveux, Groupe Hospitalier Pitié-Salpêtrière, APHP, Paris, France. 'Department of Medical Pharmacology, Lille University Hospital, Faculty of Medicine, University of Lille, Lille, France.

\section{Received: 4 March 2016 Accepted: 10 August 2016}

\section{Published online: 27 August 2016}

\section{References}

1. Bensimon $G$, Lacomblez $L$, Meininger $V$. A controlled trial of riluzole in amyotrophic lateral sclerosis. ALS/Riluzole Study Group. N Engl J Med. 1994; 330(9):585-91.

2. Soriani M-H, Desnuelle C. Épidémiologie de la SLA. Rev Neurol (Paris). 2009; 165(8-9):627-40

3. Beghi E, Logroscino G, Chiò A, Hardiman O, Mitchell D, Swingler R, et al. The epidemiology of ALS and the role of population-based registries. Biochim Biophys Acta (BBA) - Mol Basis Dis. 2006;1762(11-12):1150-7.

4. Mitchell JD, Borasio GD. Amyotrophic lateral sclerosis. Lancet. 2007; 369(9578):2031-41.

5. Turner MR, Bowser R, Bruijn L, Dupuis L, Ludolph A, Mcgrath M, et al. Mechanisms, models and biomarkers in amyotrophic lateral sclerosis. Amyotroph Lateral Scler Front Degener. 2013;14(S1):19-32.

6. Devos D, Moreau C, Devedjian JC, Kluza J, Petrault M, Laloux C, et al. Targeting Chelatable Iron as a Therapeutic Modality in Parkinson's Disease. Antioxid Redox Signal. 2014;21(2):195-210.

7. Kwan JY, Jeong SY, Van Gelderen P, Deng H-X, Quezado MM, Danielian LE, et al. Iron Accumulation in Deep Cortical Layers Accounts for MRI Signal Abnormalities in ALS: Correlating 7 Tesla MRI and Pathology. Ashizawa T, editor. PLOS ONE. 2012 Apr 17;7(4):e35241.

8. Jeong SY, Rathore KI, Schulz K, Ponka P, Arosio P, David S. Dysregulation of Iron Homeostasis in the CNS Contributes to Disease Progression in a Mouse Model of Amyotrophic Lateral Sclerosis. J Neurosci. 2009;29(3):610-9.

9. Kollewe K, Mauss U, Krampfl K, Petri S, Dengler R, Mohammadi B. ALSFRS-R score and its ratio: A useful predictor for ALS-progression. J Neurol Sci. 2008; 275(1-2):69-73.

10. Rudnicki SA, Berry JD, Ingersoll E, Archibald D, Cudkowicz ME, Kerr DA, et al. Dexpramipexole effects on functional decline and survival in subjects with amyotrophic lateral sclerosis in a Phase II study: Subgroup analysis of demographic and clinical characteristics. Amyotroph Lateral Scler Front Degener. 2013;14(1):44-51.

11. Braak H, Brettschneider J, Ludolph AC, Lee VM, Trojanowski JQ, Tredici KD. Amyotrophic lateral sclerosis - a model of corticofugal axonal spread. Nat Rev Neurol. 2013:9(12):708-14.

12. The ALS Schwaben Register Group, Rosenbohm A, Kassubek J, Weydt P, Marroquin N, Volk AE, et al. Can lesions to the motor cortex induce amyotrophic lateral sclerosis? J Neurol. 2014;261(2):283-90.

13. Ravits JM, La Spada AR. ALS motor phenotype heterogeneity, focality, and spread Deconstructing motor neuron degeneration. Neurology. 2009;73(10):805-11.

14. Stroman PW, Wheeler-Kingshott C, Bacon M, Schwab JM, Bosma R, Brooks J, et al. The current state-of-the-art of spinal cord imaging: Methods. Neuroimage. 2014;84:1070-81.

15. Verma $T$, Cohen-Adad J. Effect of respiration on the $B_{0}$ field in the human spinal cord at 3T: Effect of Respiration on B o Field in Human Spinal Cord. Magn Reson Med. 2014;72(6):1629-36.

16. Bandettini PA. What's New in Neuroimaging Methods? Ann N Y Acad Sci. 2009;1156(1):260-93.

17. Ashburner J, Friston KJ. Voxel-based morphometry-the methods. Neuroimage. 2000;11(6 Pt 1):805-21.

18. Grosskreutz J, Kaufmann J, Frädrich J, Dengler R, Heinze H-J, Peschel T. Widespread sensorimotor and frontal cortical atrophy in amyotrophic lateral sclerosis. BMC Neurol. 2006;6(1):17.

19. Mezzapesa DM, Ceccarelli A, Dicuonzo F, Carella A, De Caro MF, Lopez M, et al. Whole-brain and regional brain atrophy in amyotrophic lateral sclerosis. AJNR Am J Neuroradiol. 2007;28(2):255-9.
20. Mezzapesa DM, D’Errico E, Tortelli R, Distaso E, Cortese R, Tursi M, et al. Cortical thinning and clinical heterogeneity in amyotrophic lateral sclerosis. PLoS One. 2013;8(11):e80748.

21. Agosta F, Pagani E, Rocca MA, Caputo D, Perini M, Salvi F, et al. Voxel-based morphometry study of brain volumetry and diffusivity in amyotrophic lateral sclerosis patients with mild disability. Hum Brain Mapp. 2007;28(12):1430-8.

22. Chang JL, Lomen-Hoerth C, Murphy J, Henry RG, Kramer JH, Miller BL, et al. A voxel-based morphometry study of patterns of brain atrophy in ALS and ALS/FTLD. Neurology. 2005;65(1):75-80.

23. Canu E, Agosta F, Riva N, Sala S, Prelle A, Caputo D, et al. The topography of brain microstructural damage in amyotrophic lateral sclerosis assessed using diffusion tensor MR imaging. AJNR Am J Neuroradiol. 2011;32(7):1307-14.

24. Thivard L, Pradat P-F, Lehéricy S, Lacomblez L, Dormont D, Chiras J, et al. Diffusion tensor imaging and voxel based morphometry study in amyotrophic lateral sclerosis: relationships with motor disability. J Neurol Neurosurg Psychiatry. 2007;78(8):889-92.

25. Schuster C, Kasper E, Machts J, Bittner D, Kaufmann J, Benecke R, et al. Focal thinning of the motor cortex mirrors clinical features of amyotrophic lateral sclerosis and their phenotypes: a neuroimaging study. J Neurol. 2013; 260(11):2856-64.

26. Ellis CM, Suckling J, Amaro E, Bullmore ET, Simmons A, Williams SC, et al. Volumetric analysis reveals corticospinal tract degeneration and extramotor involvement in ALS. Neurology. 2001;57(9):1571-8.

27. Devine MS, Pannek K, Coulthard A, Mccombe PA, Rose SE, Henderson RD. Exposing asymmetric gray matter vulnerability in amyotrophic lateral sclerosis. Neurolmage Clin. 2015;7:782-7.

28. Zhang Q, Mao C, Jin J, Niu C, Bai L, Dang J, et al. Side of Limb-Onset Predicts Laterality of Gray Matter Loss in Amyotrophic Lateral Sclerosis. BioMed Res Int. 2014;2014:1-11.

29. Walhout R, Westeneng H-J, Verstraete E, Hendrikse J, Veldink JH, van den Heuvel MP, et al. Cortical thickness in ALS: towards a marker for upper motor neuron involvement. J Neurol Neurosurg Psychiatry. 2015;86(3):288-94.

30. Verstraete E, van den Heuvel MP, Veldink JH, Blanken N, Mandl RC, Hulshoff Pol HE, et al. Motor Network Degeneration in Amyotrophic Lateral Sclerosis: A Structural and Functional Connectivity Study. Zhan W, editor. PLoS ONE. 2010 Oct 27;5(10):e13664.

31. Zhu W, Fu X, Cui F, Yang F, Ren Y, Zhang X, et al. ALFF Value in Right Parahippocampal Gyrus Acts as a Potential Marker Monitoring Amyotrophic Lateral Sclerosis Progression: a Neuropsychological, Voxel-Based Morphometry, and Resting-State Functional MRI Study. J Mol Neurosci [Internet]. 2015 Jun 4 [cited 2015 Jul 29]; Available from: http://link.springer. com/10.1007/s12031-015-0583-9

32. Kassubek J, Unrath A, Huppertz H, Lulé D, Ethofer T, Sperfeld A, et al. Global brain atrophy and corticospinal tract alterations in ALS, as investigated by voxel-based morphometry of 3-D MRI. Amyotroph Lateral Scler. 2005;6(4):213-20.

33. Sach M, Winkler G, Glauche V, Liepert J, Heimbach B, Koch MA, et al. Diffusion tensor MRI of early upper motor neuron involvement in amyotrophic lateral sclerosis. Brain J Neurol. 2004;127(Pt 2):340-50.

34. Sage CA, Peeters RR, Görner A, Robberecht W, Sunaert S. Quantitative diffusion tensor imaging in amyotrophic lateral sclerosis. Neuroimage. 2007; 34(2):486-99.

35. Agosta F, Valsasina P, Riva N, Copetti M, Messina MJ, Prelle A, et al. The cortical signature of amyotrophic lateral sclerosis. PLoS One. 2012;7(8):e42816.

36. Cerami C, Dodich A, Canessa N, Crespi C, lannaccone S, Corbo M, et al. Emotional empathy in amyotrophic lateral sclerosis: a behavioural and voxel-based morphometry study. Amyotroph Lateral Scler Front Degener. 2014;15(1-2):21-9.

37. Bede P, Bokde ALW, Byrne S, Elamin M, McLaughlin RL, Kenna K, et al. Multiparametric MRI study of ALS stratified for the C9orf72 genotype. Neurology. 2013;81(4):361-9.

38. Westeneng H-J, Verstraete E, Walhout R, Schmidt R, Hendrikse J, Veldink JH, et al. Subcortical structures in amyotrophic lateral sclerosis. Neurobiol Aging [Internet]. 2014 Sep [cited 2014 Nov 6]; Available from: http://linkinghub. elsevier.com/retrieve/pii/S0197458014005971

39. Abdulla S, Machts J, Kaufmann J, Patrick K, Kollewe K, Dengler R, et al. Hippocampal degeneration in patients with amyotrophic lateral sclerosis. Neurobiol Aging. 2014;35(11):2639-45. 
40. Chapman MC, Jelsone-Swain L, Fling BW, Johnson TD, Gruis K, Welsh RC. Corpus callosum area in amyotrophic lateral sclerosis. Amyotroph Lateral Scler. 2012;13(6):589-91.

41. Meadowcroft MD, Mutic NJ, Bigler DC, Wang J, Simmons Z, Connor JR, et al. Histological-MRI correlation in the primary motor cortex of patients with amyotrophic lateral sclerosis: MRI and Histological Analysis of the PMC in ALS. J Magn Reson Imaging. 2015;41(3):665-75.

42. Le Bihan D, Mangin JF, Poupon C, Clark CA, Pappata S, Molko N, et al. Diffusion tensor imaging: concepts and applications. J Magn Reson Imaging JMRI. 2001;13(4):534-46.

43. Habas C. Basic principles of diffusion tensor MR tractography. J Radiol. 2004; 85(3):281-6

44. Yamada K, Sakai K, Akazawa K, Yuen S, Nishimura T. MR tractography: a review of its clinical applications. Magn Reson Med Sci MRMS Off J Jpn Soc Magn Reson Med. 2009;8(4):165-74

45. Ciccarelli O, Behrens TE, Johansen-Berg H, Talbot K, Orrell RW, Howard RS, et al. Investigation of white matter pathology in ALS and PLS using tractbased spatial statistics. Hum Brain Mapp. 2009;30(2):615-24.

46. Nickerson JP, Koski CJ, Boyer AC, Burbank HN, Tandan R, Filippi CG. Linear longitudinal decline in fractional anisotropy in patients with amyotrophic lateral sclerosis: preliminary results. Klin Neuroradiol. 2009;19(2):129-34.

47. Stagg CJ, Knight S, Talbot K, Jenkinson M, Maudsley AA, Turner MR. Wholebrain magnetic resonance spectroscopic imaging measures are related to disability in ALS. Neurology. 2013;80(7):610-5.

48. Yin H, Cheng SHT, Zhang J, Ma L, Gao Y, Li D, et al. Corticospinal tract degeneration in amyotrophic lateral sclerosis: a diffusion tensor imaging and fibre tractography study. Ann Acad Med Singapore. 2008;37(5):411-5.

49. Iwata NK, Aoki S, Okabe S, Arai N, Terao Y, Kwak S, et al. Evaluation of corticospinal tracts in ALS with diffusion tensor MRI and brainstem stimulation. Neurology. 2008;70(7):528-32.

50. Iwata NK, Kwan JY, Danielian LE, Butman JA, Tovar-Moll F, Bayat E, et al. White matter alterations differ in primary lateral sclerosis and amyotrophic lateral sclerosis. Brain. 2011;134(9):2642-55

51. Ellis CM, Simmons A, Jones DK, Bland J, Dawson JM, Horsfield MA, et al. Diffusion tensor MRI assesses corticospinal tract damage in ALS. Neurology. 1999:53(5):1051-8.

52. Sage CA, Van Hecke W, Peeters R, Sijbers J, Robberecht W, Parizel P, et al. Quantitative diffusion tensor imaging in amyotrophic lateral sclerosis: revisited. Hum Brain Mapp. 2009;30(11):3657-75.

53. Sarica A, Cerasa A, Vasta R, Perrotta P, Valentino P, Mangone G, et al. Tractography in amyotrophic lateral sclerosis using a novel probabilistic tool: a study with tract-based reconstruction compared to voxel-based approach. J Neurosci Methods. 2014;224:79-87.

54. Schimrigk SK, Bellenberg B, Schlüter M, Stieltjes B, Drescher R, Rexilius J, et al. Diffusion tensor imaging-based fractional anisotropy quantification in the corticospinal tract of patients with amyotrophic lateral sclerosis using a probabilistic mixture model. AJNR Am J Neuroradiol. 2007;28(4):724-30

55. Foerster BR, Carlos RC, Dwamena BA, Callaghan BC, Petrou M, Edden RAE, et al. Multimodal MRI as a diagnostic biomarker for amyotrophic lateral sclerosis. Ann Clin Transl Neurol. 2014;1(2):107-14.

56. Filippini N, Douaud G, MacKay CE, Knight S, Talbot K, Turner MR. Corpus callosum involvement is a consistent feature of amyotrophic lateral sclerosis. Neurology. 2010;75(18):1645-52.

57. Rosskopf J, Müller H-P, Dreyhaupt J, Gorges M, Ludolph AC, Kassubek J. Ex post facto assessment of diffusion tensor imaging metrics from different MRI protocols: Preparing for multicentre studies in ALS. Amyotroph Lateral Scler Front Degener. 2015;9:1-10.

58. Tang M, Chen X, Zhou Q, Liu B, Liu Y, Liu S, et al. Quantitative assessment of amyotrophic lateral sclerosis with diffusion tensor imaging in $3.0 \mathrm{~T}$ magnetic resonance. Int J Clin Exp Med. 2015;8(5):8295-303.

59. Pyra T, Hui B, Hanstock C, Concha L, Wong JCT, Beaulieu C, et al. Combined structural and neurochemical evaluation of the corticospinal tract in amyotrophic lateral sclerosis. Amyotroph Lateral Scler. 2010; 11(1-2):157-65.

60. Prell T, Peschel T, Hartung V, Kaufmann J, Klauschies R, Bodammer N, et al. Diffusion tensor imaging patterns differ in bulbar and limb onset amyotrophic lateral sclerosis. Clin Neurol Neurosurg. 2013;115(8):1281-7.

61. Keil C, Prell T, Peschel T, Hartung V, Dengler R, Grosskreutz J. Longitudinal diffusion tensor imaging in amyotrophic lateral sclerosis. BMC Neurosci. 2012;13(1):141.
62. Zhang Y, Schuff N, Woolley SC, Chiang GC, Boreta L, Laxamana J, et al. Progression of white matter degeneration in amyotrophic lateral sclerosis: A diffusion tensor imaging study. Amyotroph Lateral Scler. 2011;12(6):421-9.

63. Rajagopalan V, Allexandre D, Yue GH, Pioro EP. Diffusion Tensor Imaging Evaluation of Corticospinal Tract Hyperintensity in Upper Motor NeuronPredominant ALS Patients. J Aging Res. 2011;2011:481745.

64. Abe O, Yamada H, Masutani Y, Aoki S, Kunimatsu A, Yamasue H, et al. Amyotrophic lateral sclerosis: diffusion tensor tractography and voxel-based analysis. NMR Biomed. 2004;17(6):411-6.

65. Poujois A, Schneider FC, Faillenot I, Camdessanché J-P, Vandenberghe N, Thomas-Antérion C, et al. Brain plasticity in the motor network is correlated with disease progression in amyotrophic lateral sclerosis: Functional Cerebral Reorganization, Disease Progression, and ALS. Hum Brain Mapp. 2013;34(10):2391-401.

66. Müller H-P, Lulé D, Unrath A, Ludolph AC, Riecker A, Kassubek J. Complementary image analysis of diffusion tensor imaging and 3dimensional t1-weighted imaging: white matter analysis in amyotrophic lateral sclerosis. J Neuroimaging Off J Am Soc Neuroimaging. 2011;21(1):24-33.

67. Chapman MC, Jelsone-Swain L, Johnson TD, Gruis KL, Welsh RC. Diffusion tensor MRI of the corpus callosum in amyotrophic lateral sclerosis: DTI of the Corpus Callosum in ALS. J Magn Reson Imaging. 2014;39(3):641-7.

68. Keller J, Vymazal J, Ridzoň P, Rusina R, Kulišt'ák P, Malíková H, et al. Quantitative brain MR imaging in amyotrophic lateral sclerosis. Magma N Y N. 2011:24(2):67-76.

69. Metwalli NS, Benatar M, Nair G, Usher S, Hu X, Carew JD. Utility of axial and radial diffusivity from diffusion tensor MRI as markers of neurodegeneration in amyotrophic lateral sclerosis. Brain Res. 2010;1348:156-64.

70. Prudlo J, Bißbort C, Glass A, Grossmann A, Hauenstein K, Benecke R, et al. White matter pathology in ALS and lower motor neuron ALS variants: a diffusion tensor imaging study using tract-based spatial statistics. J Neurol. 2012;259(9):1848-59.

71. Wang S, Poptani H, Bilello M, Wu X, Woo JH, Elman LB, et al. Diffusion tensor imaging in amyotrophic lateral sclerosis: volumetric analysis of the corticospinal tract. Am J Neuroradiol. 2006;27(6):1234-8.

72. Brettschneider J, Del Tredici K, Toledo JB, Robinson JL, Irwin DJ, Grossman $M$, et al. Stages of pTDP-43 pathology in amyotrophic lateral sclerosis: ALS Stages. Ann Neurol. 2013;74(1):20-38.

73. Kassubek J, Muller H-P, Del Tredici K, Brettschneider J, Pinkhardt EH, Lule D, et al. Diffusion tensor imaging analysis of sequential spreading of disease in amyotrophic lateral sclerosis confirms patterns of TDP-43 pathology. Brain. 2014;137(6):1733-40

74. Ding X-Q, Kollewe K, Blum K, Körner S, Kehbel S, Dengler R, et al. Value of quantitative analysis of routine clinical MRI sequences in ALS. Amyotroph Lateral Scler. 2011;12(6):406-13.

75. Bede P, Elamin M, Byrne S, McLaughlin RL, Kenna K, Vajda A, et al. Patterns of cerebral and cerebellar white matter degeneration in ALS. J Neurol Neurosurg Psychiatry. 2015;86(4):468-70.

76. Jacob S, Finsterbusch J, Weishaupt JH, Khorram-Sefat D, Frahm J, Ehrenreich H. Diffusion tensor imaging for long-term follow-up of corticospinal tract degeneration in amyotrophic lateral sclerosis. Neuroradiology. 2003:45(9):598-600.

77. Menke RAL, Abraham I, Thiel CS, Filippini N, Knight S, Talbot K, et al. Fractional Anisotropy in the Posterior Limb of the Internal Capsule and Prognosis in Amyotrophic Lateral Sclerosis. Arch Neurol. 2012;69(11):1493.

78. Menke RAL, Korner S, Filippini N, Douaud G, Knight S, Talbot K, et al. Widespread grey matter pathology dominates the longitudinal cerebral MRI and clinical landscape of amyotrophic lateral sclerosis. Brain. 2014;137(9):2546-55.

79. Lombardo F, Frijia F, Bongioanni P, Canapicchi R, Minichilli F, Bianchi F, et al. Diffusion tensor MRI and MR spectroscopy in long lasting upper motor neuron involvement in amyotrophic lateral sclerosis. Arch Ital Biol. 2009; 147(3):69-82

80. Cardenas-Blanco A, Machts J, Acosta-Cabronero J, Kaufmann J, Abdulla S, Kollewe $\mathrm{K}$, et al. Central white matter degeneration in bulbar- and limbonset amyotrophic lateral sclerosis. J Neurol. 2014;261(10):1961-7.

81. Foerster BR, Dwamena BA, Petrou M, Carlos RC, Callaghan BC, Churchill CL, et al. Diagnostic accuracy of diffusion tensor imaging in amyotrophic lateral sclerosis: a systematic review and individual patient data meta-analysis. Acad Radiol. 2013;20(9):1099-106.

82. Galanaud D, Nicoli F, Confort-Gouny S, Le Fur Y, Dormont D, Girard N, et al. Brain magnetic resonance spectroscopy. J Radiol. 2007;88(3 Pt 2):483-96. 
83. Jissendi Tchofo P, Balériaux D. Brain (1)H-MR spectroscopy in clinical neuroimaging at 3T. J Neuroradiol. 2009;36(1):24-40.

84. Soares DP, Law M. Magnetic resonance spectroscopy of the brain: review of metabolites and clinical applications. Clin Radiol. 2009;64(1):12-21.

85. Han J, Ma L. Study of the features of proton MR spectroscopy ((1)H-MRS) on amyotrophic lateral sclerosis. J Magn Reson Imaging JMRI. 2010;31(2):305-8.

86. Rooney WD, Miller RG, Gelinas D, Schuff N, Maudsley AA, Weiner MW. Decreased $\mathrm{N}$-acetylaspartate in motor cortex and corticospinal tract in ALS. Neurology. 1998;50(6):1800-5.

87. Liu C, Jiang R, Yi X, Zhu W, Bu B. Role of diffusion tensor imaging or magnetic resonance spectroscopy in the diagnosis and disability assessment of amyotrophic lateral sclerosis. J Neurol Sci. 2015;348(1-2):206-10.

88. Kalra S, Vitale A, Cashman NR, Genge A, Arnold DL. Cerebral degeneration predicts survival in amyotrophic lateral sclerosis. J Neurol Neurosurg Psychiatry. 2006;77(11):1253-5.

89. Kalra S, Hanstock CC, Martin WW, Allen PS, Johnston WS. Detection of cerebral degeneration in amyotrophic lateral sclerosis using high-field magnetic resonance spectroscopy. Arch Neurol. 2006;63(8):1144-8.

90. Cervo A, Cocozza S, Saccà F, Giorgio SMDA, Morra VB, Tedeschi E, et al. The combined use of conventional MRI and MR spectroscopic imaging increases the diagnostic accuracy in amyotrophic lateral sclerosis. Eur J Radiol. 2015;84(1):151-7.

91. Pohl C, Block W, Träber F, Schmidt S, Pels H, Grothe C, et al. Proton magnetic resonance spectroscopy and transcranial magnetic stimulation for the detection of upper motor neuron degeneration in ALS patients. J Neurol Sci. 2001;190(1-2):21-7.

92. Govind V, Sharma KR, Maudsley AA, Arheart KL, Saigal G, Sheriff S. Comprehensive evaluation of corticospinal tract metabolites in amyotrophic lateral sclerosis using whole-brain 1H MR spectroscopy. PLoS One. 2012;7(4):e35607.

93. Verma G, Woo JH, Chawla S, Wang S, Sheriff S, Elman LB, et al. Whole-brain analysis of amyotrophic lateral sclerosis by using echo-planar spectroscopic imaging. Radiology. 2013;267(3):851-7.

94. Bowen BC, Pattany PM, Bradley WG, Murdoch JB, Rotta F, Younis AA, et al MR imaging and localized proton spectroscopy of the precentral gyrus in amyotrophic lateral sclerosis. Am J Neuroradiol. 2000;21(4):647-58.

95. Foerster BR, Callaghan BC, Petrou M, Edden RAE, Chenevert TL, Feldman EL. Decreased motor cortex $\gamma$-aminobutyric acid in amyotrophic lateral sclerosis. Neurology. 2012;78(20):1596-600.

96. Unrath A, Ludolph AC, Kassubek J. Brain metabolites in definite amyotrophic lateral sclerosis: A longitudinal proton magnetic resonance spectroscopy study. J Neurol. 2007;254(8):1099-106.

97. Wang Q, Zhang X, Chen S, Zhang X, Zhang S, Youdium M, et al. Prevention of Motor Neuron Degeneration by Novel Iron Chelators in SOD1(G93A) Transgenic Mice of Amyotrophic Lateral Sclerosis. Neurodegener Dis. 2011;8(5):310-21.

98. Deistung A, Schäfer A, Schweser F, Biedermann U, Turner R, Reichenbach JR. Toward in vivo histology: A comparison of quantitative susceptibility mapping (QSM) with magnitude-, phase-, and R2*-imaging at ultra-high magnetic field strength. Neuroimage. 2013;65:299-314

99. Haacke EM, Cheng NYC, House MJ, Liu Q, Neelavalli J, Ogg RJ, et al. Imaging iron stores in the brain using magnetic resonance imaging. Magn Reson Imaging. 2005;23(1):1-25.

100. Adachi Y, Sato N, Saito Y, Kimura Y, Nakata Y, Ito K, et al. Usefulness of SWI for the Detection of Iron in the Motor Cortex in Amyotrophic Lateral Sclerosis: Usefulness of SWI for the Diagnoses of ALS. J Neuroimaging. 2015;25(3):443-51.

101. Chavhan GB, Babyn PS, Thomas B, Shroff MM, Haacke EM. Principles, Techniques, and Applications of T2*-based MR Imaging and Its Special Applications1. RadioGraphics. 2009;29(5):1433-49.

102. Haacke EM, Miao Y, Liu M, Habib CA, Katkuri Y, Liu T, et al. Correlation of putative iron content as represented by changes in R2* and phase with age in deep gray matter of healthy adults. J Magn Reson Imaging JMRI. 2010; 32(3):561-76.

103. Langkammer C, Krebs N, Goessler W, Scheurer E, Ebner F, Yen K, et al. Quantitative MR imaging of brain iron: a postmortem validation study. Radiology. 2010;257(2):455-62.

104. Haacke EM, Liu S, Buch S, Zheng W, Wu D, Ye Y. Quantitative susceptibility mapping: current status and future directions. Magn Reson Imaging. 2015; 33(1):1-25.

105. Langkammer C, Schweser F, Krebs N, Deistung A, Goessler W, Scheurer E, et al. Quantitative susceptibility mapping (QSM) as a means to measure brain iron? A post mortem validation study. Neuroimage. 2012;62(3):1593-9.
106. Oba H, Araki T, Ohtomo K, Monzawa S, Uchiyama G, Koizumi K, et al. Amyotrophic lateral sclerosis: T2 shortening in motor cortex at MR imaging. Radiology. 1993;189(3):843-6.

107. Hecht MJ, Fellner C, Schmid A, Neundörfer B, Fellner FA. Cortical T2 signal shortening in amyotrophic lateral sclerosis is not due to iron deposits. Neuroradiology. 2005:47(11):805-8.

108. Ignjatović A, Stević Z, Lavrnić S, Daković M, Bačić G. Brain iron MRI: A biomarker for amyotrophic lateral sclerosis: Brain Iron MRI: A Biomarker for ALS. J Magn Reson Imaging. 2013;38(6):1472-9.

109. Yu J, Qi F, Wang N, Gao P, Dai S, Lu Y, et al. Increased iron level in motor cortex of amyotrophic lateral sclerosis patients: An in vivo MR study. Amyotroph Lateral Scler Front Degener. 2014;15(5-6):357-61.

110. Langkammer C, Enzinger C, Quasthoff S, Grafenauer P, Soellinger M, Fazekas $\mathrm{F}$, et al. Mapping of iron deposition in conjunction with assessment of nerve fiber tract integrity in amyotrophic lateral sclerosis. J Magn Reson Imaging JMRI. 2010;31(6):1339-45.

111. Prell T, Hartung V, Tietz F, Penzlin S, Ilse B, Schweser F, et al. SusceptibilityWeighted Imaging Provides Insight into White Matter Damage in Amyotrophic Lateral Sclerosis. Kassubek J, editor. PLOS ONE. 2015 Jun 25; 10(6):e0131114

112. Schweitzer AD, Liu T, Gupta A, Zheng K, Seedial S, Shtilbans A, et al. Quantitative Susceptibility Mapping of the Motor Cortex in Amyotrophic Lateral Sclerosis and Primary Lateral Sclerosis. Am J Roentgenol. 2015;204(5):1086-92.

113. Branco LMT, De Albuquerque M, De Andrade HMT, Bergo FPG, Nucci $A$, França MC. Spinal cord atrophy correlates with disease duration and severity in amyotrophic lateral sclerosis. Amyotroph Lateral Scler Front Degener. 2014;15(1-2):93-7.

114. Cohen-Adad J, Mendili M-ME, Morizot-Koutlidis R, Lehéricy S, Meininger V, Blancho S, et al. Involvement of spinal sensory pathway in ALS and specificity of cord atrophy to lower motor neuron degeneration. Amyotroph Lateral Scler Front Degener. 2013;14(1):30-8.

115. El Mendili M-M, Cohen-Adad J, Pelegrini-Issac M, Rossignol S, MorizotKoutlidis R, Marchand-Pauvert V, et al. Multi-parametric spinal cord MRI as potential progression marker in amyotrophic lateral sclerosis. PLoS One. 2014;9(4):e95516.

116. Iglesias C, Sangari S, El Mendili M-M, Benali H, Marchand-Pauvert V, Pradat P-F. Electrophysiological and spinal imaging evidences for sensory dysfunction in amyotrophic lateral sclerosis. BMJ Open. 2015;5(2):e007659.

117. Ikeda K, Murata K, Kawase Y, Kawabe K, Kano O, Yoshii Y, et al. Relationship between cervical cord $1 \mathrm{H}$-magnetic resonance spectroscopy and clinocoelectromyographic profile in amyotrophic lateral sclerosis. Muscle Nerve. 2013;47(1):61-7.

118. Barkhof F, Haller S, Rombouts SARB. Resting-state functional MR imaging: a new window to the brain. Radiology. 2014;272(1):29-49.

119. Habas C. Physiological basis of functional MRI. J Radiol. 2002;83(11):1737-41.

120. Delmaire C, Krainik A, Lethuc V, Reyns N, Duffau H, Capelle L, et al. Functional magnetic resonance imaging: physiopathology, techniques and applications. J Radiol. 2007:88(3 Pt 2):497-509.

121. Gore JC. Principles and practice of functional MRI of the human brain. J Clin Invest. 2003;112(1):4-9.

122. Raichle ME. The Restless Brain. Brain Connect. 2011;1(1):3-12.

123. Agosta F, Canu E, Valsasina P, Riva N, Prelle A, Comi G, et al. Divergent brain network connectivity in amyotrophic lateral sclerosis. Neurobiol Aging. 2013;34(2):419-27

124. Jelsone-Swain LM, Fling BW, Seidler RD, Hovatter R, Gruis K, Welsh RC. Reduced Interhemispheric Functional Connectivity in the Motor Cortex during Rest in Limb-Onset Amyotrophic Lateral Sclerosis. Front Syst Neurosci [Internet]. 2010 [cited 2015 Jul 15];4. Available from: http://journal. frontiersin.org/article/10.3389/fnsys.2010.00158/abstract

125. Agosta F, Valsasina P, Absinta M, Riva N, Sala S, Prelle A, et al. Sensorimotor Functional Connectivity Changes in Amyotrophic Lateral Sclerosis. Cereb Cortex. 2011;21(10):2291-8.

126. Mohammadi B, Kollewe K, Samii A, Krampfl K, Dengler R, Münte TF. Changes of resting state brain networks in amyotrophic lateral sclerosis. Exp Neurol. 2009;217(1):147-53.

127. Douaud G, Filippini N, Knight S, Talbot K, Turner MR. Integration of structural and functional magnetic resonance imaging in amyotrophic lateral sclerosis. Brain. 2011;134(12):3470-9.

128. Luo C, Chen Q, Huang R, Chen X, Chen K, Huang X, et al. Patterns of Spontaneous Brain Activity in Amyotrophic Lateral Sclerosis: A Resting-State fMRI Study. Duce JA, editor. PLoS ONE. 2012 Sep 20;7(9):e45470. 
129. Mohammadi B, Kollewe K, Samii A, Dengler R, Münte TF. Functional neuroimaging at different disease stages reveals distinct phases of neuroplastic changes in amyotrophic lateral sclerosis. Hum Brain Mapp. 2011;32(5):750-8.

130. Mohammadi B, Kollewe K, Cole DM, Fellbrich A, Heldmann M, Samii A, et al. Amyotrophic lateral sclerosis affects cortical and subcortical activity underlying motor inhibition and action monitoring: ALS and Motor Inhibition. Hum Brain Mapp. 2015;36(8):2878-89.

131. Kollewe K, Münte TF, Samii A, Dengler R, Petri S, Mohammadi B. Patterns of cortical activity differ in ALS patients with limb and/or bulbar involvement depending on motor tasks. J Neurol. 2011;258(5):804-10.

132. Konrad C, Henningsen H, Bremer J, Mock B, Deppe M, Buchinger C, et al. Pattern of cortical reorganization in amyotrophic lateral sclerosis: a functional magnetic resonance imaging study. Exp Brain Res. 2002;143(1):51-6.

133. Schoenfeld MA, Tempelmann C, Gaul C, Kühnel GR, Düzel E, Hopf J-M, et al. Functional motor compensation in amyotrophic lateral sclerosis. J Neurol. 2005;252(8):944-52.

134. Lule D, Diekmann V, Muller H-P, Kassubek J, Ludolph AC, Birbaumer N. Neuroimaging of multimodal sensory stimulation in amyotrophic lateral sclerosis. J Neurol Neurosurg Psychiatry. 2010;81(8):899-906.

135. Stoppel CM, Vielhaber S, Eckart C, Machts J, Kaufmann J, Heinze H-J, et al. Structural and functional hallmarks of amyotrophic lateral sclerosis progression in motor- and memory-related brain regions. Neurolmage Clin. 2014;5:277-90

136. Jelsone-Swain L, Persad C, Burkard D, Welsh RC. Action Processing and Mirror Neuron Function in Patients with Amyotrophic Lateral Sclerosis: An fMRI Study. lacoboni M, editor. PLOS ONE. 2015 Apr 17;10(4):e0119862.

137. Bede P, Hardiman O. Lessons of ALS imaging: Pitfalls and future directions A critical review. Neurolmage Clin. 2014;4:436-43.

138. Brooks BR, Miller RG, Swash M, Munsat TL, World Federation of Neurology Research Group on Motor Neuron Diseases. El Escorial revisited: revised criteria for the diagnosis of amyotrophic lateral sclerosis. Amyotroph Lateral Scler Mot Neuron Disord Off Publ World Fed Neurol Res Group Mot Neuron Dis. 2000; 1(5):293-9.

139. Andersen PM, Borasio GD, Dengler R, Hardiman O, Kollewe K, Leigh PN, et al. EFNS task force on management of amyotrophic lateral sclerosis: guidelines for diagnosing and clinical care of patients and relatives. Eur J Neurol. 2005;12(12):921-38.

140. Turner MR, Kiernan MC, Leigh PN, Talbot K. Biomarkers in amyotrophic lateral sclerosis. Lancet Neurol. 2009;8(1):94-109.

141. Pradat P-F, Bruneteau G. [Clinical characteristics of amyotrophic lateral sclerosis subsets]. Rev Neurol (Paris). 2006 Jun;162 Spec No 2:4S29-24S33.

142. Zoccolella S, Beghi E, Palagano G, Fraddosio A, Samarelli V, Lamberti P, et al. Predictors of delay in the diagnosis and clinical trial entry of amyotrophic lateral sclerosis patients: a population-based study. J Neurol Sci. 2006;250(12):45-9.

143. Pradat P-F, El Mendili M-M. Neuroimaging to investigate multisystem involvement and provide biomarkers in amyotrophic lateral sclerosis. BioMed Res Int. 2014;2014:467560.

144. Turner MR, Grosskreutz J, Kassubek J, Abrahams S, Agosta F, Benatar M, et al. Towards a neuroimaging biomarker for amyotrophic lateral sclerosis. Lancet Neurol. 2011;10(5):400-3.

145. Filippi M, Agosta F, Grosskreutz J, Benatar M, Kassubek J, Verstraete E, et al. Progress towards a neuroimaging biomarker for amyotrophic lateral sclerosis. Lancet Neurol. 2015;14(8):786-8.

146. Müller H-P, Turner MR, Grosskreutz J, Abrahams S, Bede P, Govind V, et al. A large-scale multicentre cerebral diffusion tensor imaging study in amyotrophic lateral sclerosis. J Neurol Neurosurg Psychiatry. 2016;87(6):570-9.

\section{Submit your next manuscript to BioMed Central and we will help you at every step:}

- We accept pre-submission inquiries

- Our selector tool helps you to find the most relevant journal

- We provide round the clock customer support

- Convenient online submission

- Thorough peer review

- Inclusion in PubMed and all major indexing services

- Maximum visibility for your research

Submit your manuscript at www.biomedcentral.com/submit

) Biomed Central 